Stereochemistry Research Group of the Hungarian Academy of Sciences

Institute of Pharmaceutical Chemistry

University of Szeged

\title{
Enantioselective hydrogenations of $\alpha, \beta$-unsaturated carboxylic acids over a cinchonidine-modified palladium catalyst
}

\author{
PhD Thesis \\ Beáta Hermán
}

Supervisors:

Dr. György Szőllősi

Prof. Dr. Ferenc Fülöp

Szeged

2011 


\section{CONTENTS}

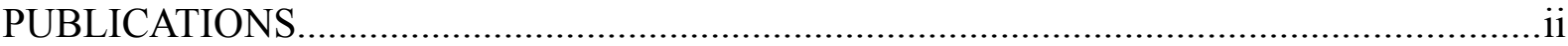

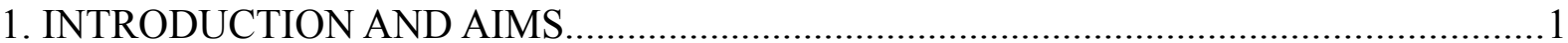

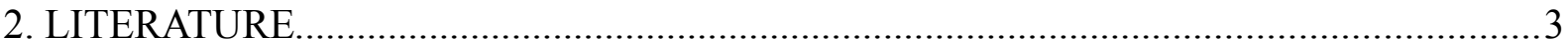

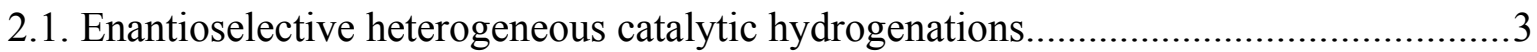

2.1.1. Heterogenization of chiral metal complexes....................................................... 3

2.1.2. Chiral modification of heterogeneous metal catalysts...........................................4

2.2. Enantioselective hydrogenations of unsaturated carboxylic acids over modified

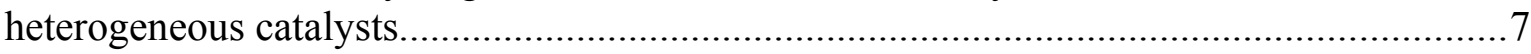

2.2.1. Hydrogenations of unsaturated carboxylic acids bearing aromatic substituents

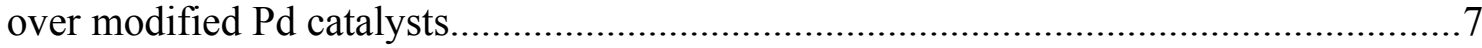

2.2.2. Hydrogenations of aliphatic unsaturated carboxylic acids over Pd catalysts modified with cinchona alkaloids.

2.2.3. Hydrogenations of unsaturated dicarboxylic acids over cinchona-modified Pd catalysts.

2.2.4. Hydrogenations of heteroaromatic carboxylic acids over cinchona-modified Pd catalysts.

2.2.5. Hydrogenations of dehydroamino acid derivatives and unsaturated carboxylic

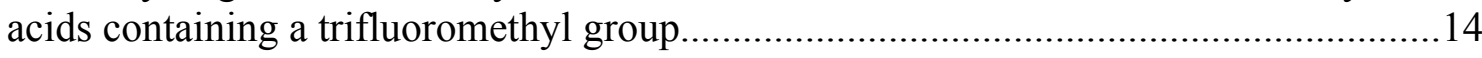

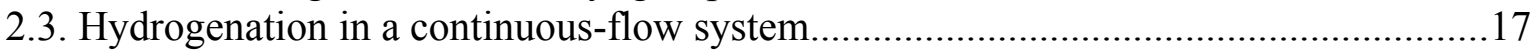

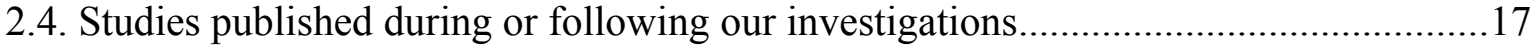

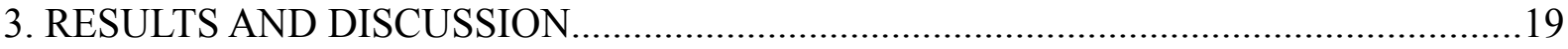

3.1. Hydrogenations of unsaturated $\alpha, \beta$-carboxylic acids in a batch reactor.......................19

3.1.1 Preparation of the unsaturated $\alpha, \beta$-carboxylic acids......................................... 19

3.1.2. Choice of the corresponding solvent and catalyst...........................................21

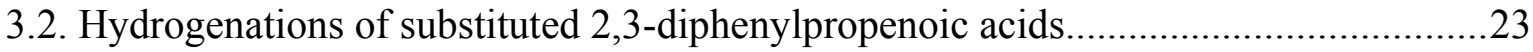

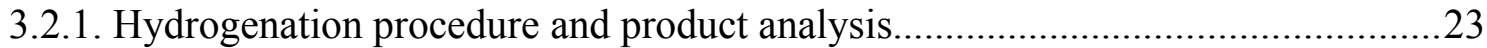

3.2.2. Hydrogenations of monomethoxy- or fluorine-substituted derivatives................24

3.2.3. Hydrogenations of dimethoxy derivatives.........................................................29

3.2.4. Hydrogenations of mixed methoxy- and fluoro-disubstituted derivatives.............31

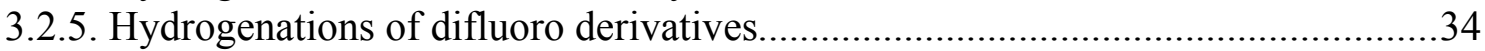

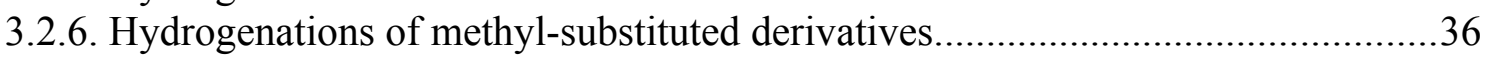

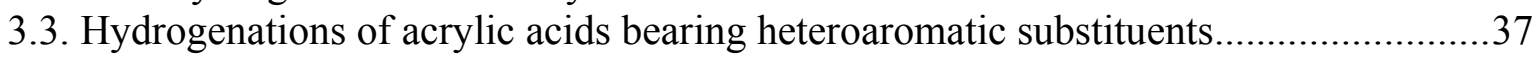

3.4. Hydrogenations of $\alpha, \beta$-unsaturated carboxylic acids in a high-pressure continuous-

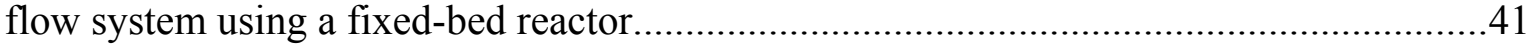

3.4.1. Hydrogenation procedures and product analysis..................................................4 41

3.4.2. Hydrogenations of (E)-2-methyl-2-butenoic and (E)-2-methyl-2-hexenoic acids 42

3.4.3. Hydrogenations of (E)-2,3-diphenylpropenoic acid and itaconic acid.................44

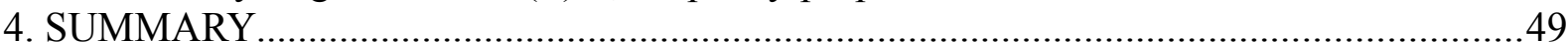

5. REFERENCES

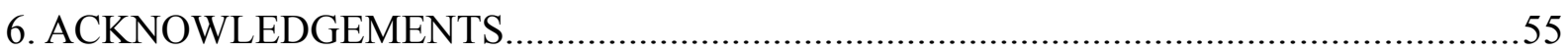

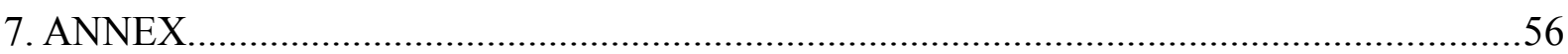




\section{PUBLICATIONS}

\section{Papers related to the thesis}

I. Beáta Hermán, György Szőllősi, Ferenc Fülöp, Mihály Bartók

Enantioselective hydrogenation of $\alpha, \beta$-unsaturated carboxylic acids in fixed-bed reactor Applied Catalysis A: General 2007, 331, 39. $\quad$ IF $=3.166$

II. György Szőllösi, Beáta Hermán, Károly Felföldi, Ferenc Fülöp, Mihály Bartók Effect of the substituent position on the enantioselective hydrogenation of methoxysubstituted 2,3-diphenylpropenoic acids over palladium catalyst Journal of Molecular Catalysis A: Chemical 2008, 290, $54 . \quad$ IF $=2.814$

III. György Szőllősi, Beáta Hermán, Károly Felföldi, Ferenc Fülöp, Mihály Bartók Up to $96 \%$ enantioselectivities in the hydrogenation of fluorine substituted $(E)$-2,3diphenylpropenoic acids over cinchonidine-modified palladium catalyst Advanced Synthesis and Catalysis 2008, 350, $2804 . \quad$ IF = 5.619

IV. Beáta Hermán, György Szőllősi, Károly Felföldi, Ferenc Fülöp, Mihály Bartók Enantioselective hydrogenation of propenoic acids bearing heteroatomic substituent over cinchonidine modified $\mathrm{Pd} /$ alumina

Catalysis Communications 2009, 10, 1107.

$\mathrm{IF}=2.791$

\section{Other papers}

V. György Szőllősi, Beáta Hermán, Ferenc Fülöp, Mihály Bartók Continuous enantioselective hydrogenation of activated ketones on a Pt-CD chiral catalyst: use of H-Cube reactor system Reaction Kinetics and Catalysis Letters 2006, 88, 391. $\mathrm{IF}=0.514$

VI. György Szöllősi, Beáta Hermán, Erika Szabados, Ferenc Fülöp, Mihály Bartók On the scope of the cinchonidine-modified Pd catalyst in enantioselective hydrogenation; adsorption mode of $(E)$-2,3-diphenylpropenoic acids evidenced by chlorine substituted derivatives Journal of Molecular Catalysis A: Chemical 2010, 333, 28. $\mathrm{IF}=3.135$

VII. György Szőllősi, Beáta Hermán, Ferenc Fülöp, Mihály Bartók

Cinchona methyl ethers as modifiers in the enantioselective hydrogenation of $(E)$-2,3diphenylpropenoic acids over Pd catalyst Journal of Catalysis 2010, 276, 259. IF $=5.288$ 


\section{Conference lectures}

VIII. Hermán Beáta, Szőllősi György

Enantioszelektív hidrogénezések királisan módosított heterogén katalizátorokon folyamatos rendszerben

XXIX. Kémiai Elöadói Napok

Szeged, 2006. október 30-31. Abstr.: 60.

IX. Hermán Beáta, Szőllősi György, Felföldi Károly, Fülöp Ferenc, Bartók Mihály Szubsztituált $\alpha, \beta$-diaril akrilsav származékok enantioszelektív hidrogénezése Magyar Kémikusok Egyesülete, Centenáriumi Vegyészkonferencia Sopron, 2007. május 29 - június 1. Abstr.: SZ-P-22

X: György Szőllősi, Kornél Szőri, Beáta Hermán, Szabolcs Cserényi, Károly Felföldi, Ferenc Fülöp, Mihály Bartók

Scope of the cinchona alkaloids-modified palladium catalysts in enantioselective hydrogenation of unsaturated carboxylic acids

EuropaCat VIII

Turku, Finland, August 26-31, 2007, Abstr.: 5-13.

XI. Hermán Beáta, Szőllősi György

Metoxi-szubsztituált $\alpha$-fenilfahéjsav származékok enantioszelektív hidrogénezése királisan módosított heterogén katalizátorokon

XXX. Kémiai Elöadói Napok

Szeged, 2007. október 29-31. Abstr.: 73.

XII. Hermán Beáta, Szőllősi György, Felföldi Károly, Fülöp Ferenc, Bartók Mihály Metoxi- és fluor-szubsztituált $\alpha$-fenilfahéjsav származékok enantioszelektív hidrogénezése királisan módosított heterogén katalizátoron Magyar Kémikusok Egyesülete, Vegyészkonferencia Hajdúszoboszló, 2008. június 19-21. Abstr.: P-29

XIII. György Szőllősi, Beáta Hermán, Károly Felföldi, Ferenc Fülöp, Mihály Bartók Heterogeneous enantioselective hydrogenations of heteroatomic analogs of $(E)$ - $\alpha$ phenylcinnamic acid

Tenth International Symposium on Heterogeneous Catalysis

Varna, Bulgaria, August 23-27, 2008, Abstr.: P-35 
XIV. Hermán Beáta, Szőllősi György

Metoxi- és fluor-szubsztituált $\alpha$-fenilfahéjsav származékok enantioszelektív

hidrogénezése

XXXI. Kémiai Elöadói Napok

Szeged, 2008. október 27-29. Abstr.: 85.

XV. György Szőllősi, Beáta Hermán, Ferenc Fülöp, Mihály Bartók

Effect of modifier structure on the enantioselective hydrogenation of substituted $(E)$ -

2,3-diphenylpropenoic acids over palladium catalyst

EuropaCat IX Catalysis for a Sustainable World

Salamanca, Spain, $30^{\text {th }}$ August $-4^{\text {th }}$ September 2009. Abstr.: P2-73 


\section{INTRODUCTION AND AIMS}

Optically pure carboxylic acids and their substituted derivatives are essential pharmaceuticals or chiral building blocks used in the preparation of biologically active compounds [1-3]. Among the most convenient procedures for the preparation of chiral carboxylic acids are the asymmetric hydrogenations of the corresponding prochiral unsaturated carboxylic acids [4-6]. Following the development of a large variety of highly enantioselective chiral noble metal complexes, these reactions gained increased industrial importance [7-10]. The optically enriched fluorinated products are also of considerable practical importance. The exceptional chemical and pharmaceutical properties of fluorinated compounds promoted the development of asymmetric methods for the preparation of fluorinecontaining optically pure chiral building blocks [11-14], including the enantioselective hydrogenations of fluorinated prochiral substrates such as fluorinated unsaturated acids [15]. Furthermore, the presence of heteroaromatic rings in the chiral carboxylic acids may lead to versatile optically pure building blocks for the synthesis of biologically active compounds $[4,6]$.

Replacement of the highly efficient soluble catalysts by heterogeneous catalytic systems results in various economic and technical advantages, provided the heterogeneous catalysts are competitive as concerns the activities and optical purities of the saturated products. Moreover, industry prefers continuously operating methods. The large-scale production of certain optically pure compounds may lead to replacement of the widely applied discontinuously operated batch reactors with continuously operated reactor systems for the production of bulk chemicals [16-18]. The simplest approach for the development of enantioselective heterogeneous hydrogenation catalysts is the surface modification of conventional metal catalysts by chiral compounds [19-22]. However, to date only a few efficient chirally modified heterogeneous metal catalysts are known for the enantioselective hydrogenations of prochiral unsaturated compounds. Among the known catalytic systems, the cinchonidine (CD)-modified Pd catalyst has been found to be substrate-sensitive in the hydrogenations of $\alpha, \beta$-unsatured carboxylic acids. The best enantioselectivities were obtained in the hydrogenations of (E)-2,3-diphenylpropenoic acid and its methoxy-substituted derivatives. Excellent enantiomeric excess (ee) values were obtained in the hydrogenation of the para-methoxy-substituted derivatives. Since the exact structure of the intermediate complex responsible for enantioselection in these reactions is still unknown, it was difficult to 
predict the behaviour of the derivatives substituted in the ortho or meta position of either of the two phenyl rings and whether the steric effect of the methoxy substituent in a certain position would be favourable as concerns enantiodifferentiation. Accordingly, we examined the effects of methoxy substituents in different positions on both the $\alpha$-and $\beta$-phenyl rings in order to explore the reason for the ee increases observed in the hydrogenations of methoxysubstituted derivatives. A further aim of our work was to investigate the effects of a fluoro substituent on either of the phenyl rings in (E)-2,3-diphenylpropenoic acid in comparison with the unsubstituted and some relevant methoxy-substituted derivatives. Besides the fluoro- and methoxy-substituted compounds, the effects of methyl substitution in certain positions were also examined to ascertain the roles of the electronic and steric effects of the substituents. In spite of the excellent enantioselectivities obtained in the reactions of (E)-2,3diphenylpropenoic acid derivatives and the increased pharmaceutical importance of the heteroaromatic analogues of (E)-2,3-diphenylpropenoic acids, the hydrogenations of such compounds over heterogeneous catalysts have not been studied to date. We set out to extend the scope of the Pd-CD catalytic system to the enantioselective hydrogenations of propenoic acid derivatives bearing 2-furyl or 3-pyridyl moieties.

As heterogeneous catalysts are suitable for use in continuous processes, chirally modified metal catalysts are the most promising alternatives for these purposes. The behaviour of the prochiral $\alpha, \beta$-unsaturated carboxylic acids over Pd catalysts in a continuousflow system has not been reported previously. Consequently, we examined the enantioselective hydrogenations of four $\alpha, \beta$-unsaturated carboxylic acids over a $\mathrm{Pd} / \mathrm{Al}_{2} \mathrm{O}_{3}$ catalyst in a continuous-flow system, using a fixed-bed reactor, in order to test whether these compounds may be efficiently and enantioselectively hydrogenated in a continuously operated experimental set-up. 


\section{LITERATURE}

The synthesis of optically active compounds has become one of the most important fields of organic chemical research [23-26]. Using optically pure compounds is essential, particularly in the pharmaceutical industry [1], since the enantiomers of biologically active compounds may have different pharmacological effects. For the preparation of enantiopure chiral products, several methods are known. The resolution of racemic mixtures [1,2] or catalytic syntheses using chiral auxiliaries [27] are of great significance. In the latter case, the production of the optically active products is ensured by a small amount of a chiral compound [4,28]. Of the known methods, enantioselective catalytic hydrogenations have received most attention [5], due to the large variety of efficient chiral metal complexes. The use of these catalysts led to high enantioselectivities in the hydrogenations of a large variety of prochiral unsaturated compounds $[8,9,29]$. The application of metal chiral complexes has a number of practical disadvantages, such as the high price of the complexes or the need for special equipment as a result of their extreme sensitivity. Removal of catalyst from the product is difficult, and reuse is not possible in most reactions. These disadvantages can be avoided through the use of heterogeneous catalysts. The currently valid strict environmental and economic requirements have also motivated efforts to develop chiral heterogeneous catalysts [19].

\subsection{Enantioselective heterogeneous catalytic hydrogenations}

The development of chiral heterogeneous catalysts used in enantioselective hydrogenations is a rapidly progressing research field, which has already led to various useful results.

\subsubsection{Heterogenization of chiral metal complexes}

A reasonable method for the preparation of heterogeneous chiral catalysts is the anchoring of homogeneous chiral noble metal complexes on supports which do not dissolve in the applied medium. Various heterogenization processes have been developed in recent decades. The most successful methods are chemical anchoring of chiral ligands on solid supports; anchoring of complexes containing cationic metals or ionic ligands on solid supports by ion-exchange, or anchoring of metal complexes on oxide supports through the use of heteropolyacids [30-33]. The application of catalysts developed by the above-mentioned 
methods leads to excellent activities and enantioselectivities, comparable with those of the corresponding soluble metal complexes. Although the simple removal and reuse of these solid catalysts is possible, some significant disadvantages characteristic of homogeneous complexes are still observed. The high price of the complexes used for heterogenization and their sensitivity to moisture and air hinder the general practical application of this type of heterogeneous catalysts.

\subsubsection{Chiral modification of heterogeneous metal catalysts}

Immobilization of optically pure organic materials on the surface of conventional heterogeneous transition metal catalysts and their interaction with the substrate during the reaction may result in the selective formation of one optical isomer. The chiral materials most often used, called modifiers, are usually cheap natural compounds. The modifiers can be fixed on the surface of the active metals through simple adsorption. The application of such catalysts has become attractive in view of the simplicity of the method, the ease of removal of the catalyst from the reaction mixture and the possibility of reuse. Because of these advantages, the development and detailed examination of such catalytic systems is at the forefront of chemical research [20,21].

Optically pure tartaric acid-modified $\mathrm{Ni}$ catalysts, the first chiral modified heterogeneous catalysts, permitted the highly selective preparation of optically enriched products through hydrogenation of $\beta$-keto esters and $\beta$-diketones (Scheme 1) [34-36].

Furthermore, excellent ee-s were obtained by Orito et al. in the hydrogenation of $\alpha$-keto esters over cinchona alkaloid-modified Pt catalysts (Scheme 2) [37,38]. Detailed investigations of these reactions led to ee-s $90 \%$ being obtained in the hydrogenations of several $\alpha$-keto esters $[39,40]$. In the last decade, the applicability of this catalytic system was significantly extended to the hydrogenation of other activated ketones [40].

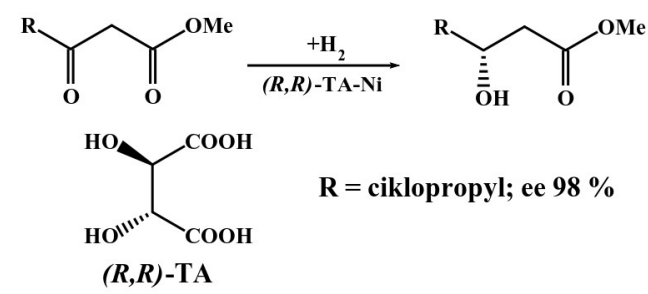

Scheme 1

Hydrogenations of $\beta$-keto esters over tartaric acid-modified Ni catalysts 


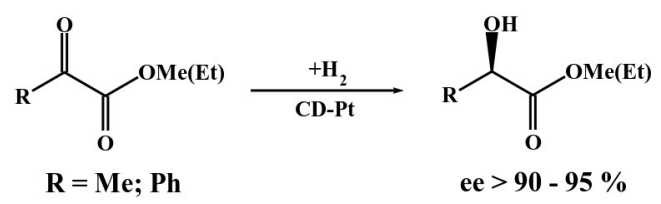

Scheme 2

Enantioselective hydrogenations of $\alpha$-keto esters over CD-modified Pt catalysts

The natural cinchona alkaloids cinchonidine (CD), cinchonine $(\mathrm{CN})$, quinine $(\mathrm{QN})$ and quinidine (QD), and their $\mathrm{C}_{9}-\mathrm{O}-\mathrm{CH}_{3}$ ethers or the 10,11-dihydro derivatives (Scheme 3) have often been used in such investigations, as they furnish the highest enantioselectivities.

The success obtained with the two enantioselective catalytic systems mentioned above resulted in their industrial application [6] and accelerated research on other modifier-metal catalyst systems, with possible application in the hydrogenations of other types of prochiral compounds. Efforts have been made to achieve the enantioselective hydrogenation of prochiral olefins and imines [41,42].

Excellent ee-s were obtained in the partial hydrogenations of substituted 2-pyrones over cinchona alkaloid-modified Pd catalysts [43]. However, the hydrogenation of the similar open-chain compound led to the saturated product being obtained in only moderate optical purity [44]. Similar results were obtained in the hydrogenation of an exocyclic $\alpha, \beta$ unsaturated ketone (Scheme 4) [45].

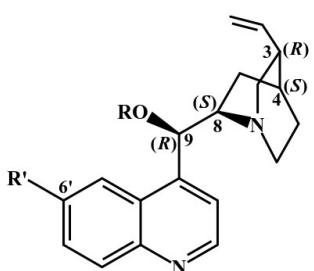

CD: $\mathbf{R}=\mathbf{H} ; \mathbf{R}^{\prime}=\mathbf{H}$

QN: $\mathbf{R}=\mathbf{H} ; \mathbf{R}^{\prime}=\mathbf{M e O}$

CD methyl ether: $R=M e ; R^{\prime}=\mathbf{H}$

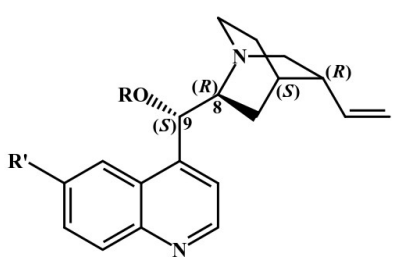

$\mathbf{C N}: \mathbf{R}=\mathbf{H} ; \mathbf{R}^{\prime}=\mathbf{H}$

QD: $\mathbf{R}=\mathbf{H} ; \mathbf{R}^{\prime}=\mathrm{MeO}$

\section{Scheme 3}

The cinchona alkaloids used as modifiers 

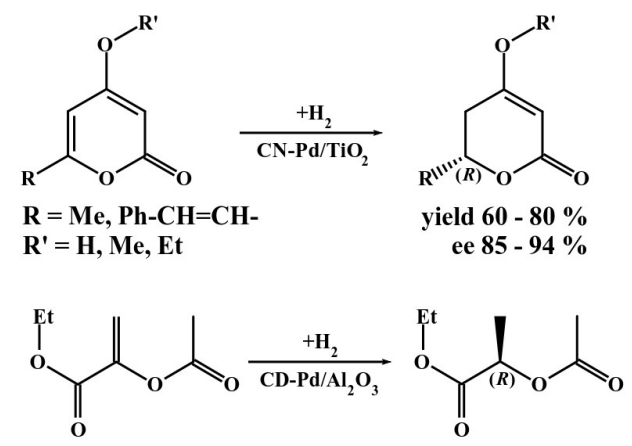

ee $50 \%$

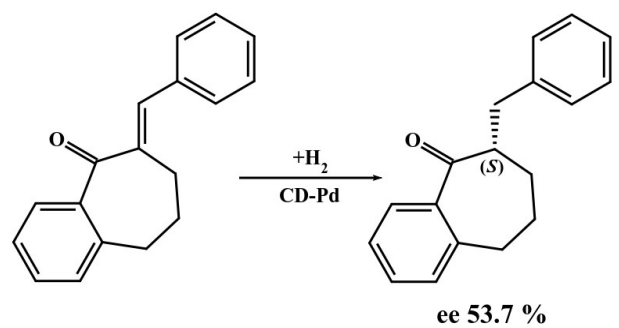

Scheme 4

Enantioselective hydrogenations of prochiral $\mathrm{C}=\mathrm{C}$ groups over cinchona alkaloid-modified $\mathrm{Pd}$ catalysts

The substrate specificity of these reactions motivated tests on other types of chiral modifiers in these reactions. The ethyl ester of (-)-dihydroapovincamine proved to be an effective modifier in the hydrogenation of isophorone, affording ( $R$ )-3,3,5-trimethylcyclohexanone in 55\% ee over a Pd catalyst (Scheme 5) [46]. The hydrogenation of isophorone became a well-studied test reaction in consequence of the results over a $\mathrm{Pd}$ catalyst in the presence of $(S)$-proline $[47,48]$. This reaction also inspired the application of other proline derivatives as modifiers: the use of $(S)$ - $\alpha, \alpha$-diphenyl-2-pyrrolidine methanol gave a medium ee (Scheme 5) [49], while proline esters and amides led to lower ee-s [50].

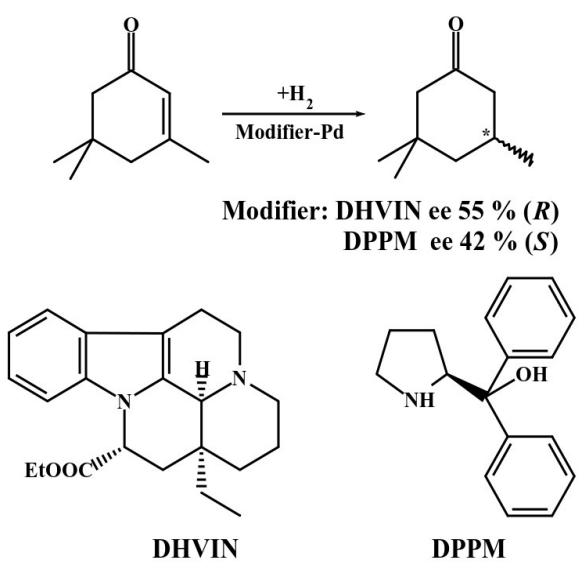

Scheme 5

Enantioselective hydrogenation of isophorone over modified Pd catalysts 


\subsection{Enantioselective hydrogenations of unsaturated carboxylic acids over modified heterogeneous catalysts}

The asymmetric synthesis of chiral carboxylic acids is of considerable importance for the pharmaceutical industry: several optically pure carboxylic acids, e.g. (S)-ibuprofen, $(S)$ ketoprofen, $(S)$-naproxen and $L$-DOPA, are well-known drugs. Additionally, an appreciable number of chiral carboxylic acid intermediates are used in the pharmaceutical, cosmetics and food industries [1,2]. Some of these compounds are produced by enantioselective hydrogenation of the corresponding $\alpha, \beta$-unsaturated carboxylic acids $[5,6]$. The significance of the development of heterogeneous catalytic systems which can be applied for this purpose is therefore high. In the early experiments, chiral supports were tried, but low ee-s were obtained in the hydrogenations of unsaturated acids with these catalysts and the results were not reproducible [51,52]. Similarly, low ee-s were obtained over Pd- or Pt- $\beta$-zeolites containing a chiral pore structure [53].

The tartaric acid-Ni catalyst afforded excellent ee-s in the hydrogenation of $\beta$-keto esters, in contrast with the hydrogenations of $(E)$-2,3-diphenylpropenoic acids and their inorganic salts [54]. The best results were obtained over Pd catalysts modified by cinchona alkaloids [55]. The ee (30\%) initially obtained in the hydrogenation of (E)-2,3diphenylpropenoic acid over $\mathrm{Pd} / \mathrm{C}$ modified by $\mathrm{CD}$ was at that time an outstanding result. Extensive investigations of the Pd-cinchona catalytic system started in the early 1990s, and led to a considerable extension of the applicability of this catalytic system and to excellent enantioselectivities with several acids.

2.2.1. Hydrogenations of unsaturated carboxylic acids bearing aromatic substituents over modified Pd catalysts

The hydrogenation of (E)-2,3-diphenylpropenoic acid over a CD-modified Pd was examined by Nitta et al. (Scheme 6) [56-64]. They extended their thorough examinations to the effect of the solvent [56,57], the structure of the support [56,59-62], the dispersion of the $\operatorname{Pd}[62]$, the method of preparation of the catalysts [62,64], the concentrations of the modifier and the acid [58], the structure of the modifier [60], the temperature [58] and the $\mathrm{H}_{2}$ pressure [63]. As a result of these studies, $(S)$-2,3-diphenylpropenoic acid could be prepared in the presence of $\mathrm{CD}$ in up to $72 \%$ ee. 

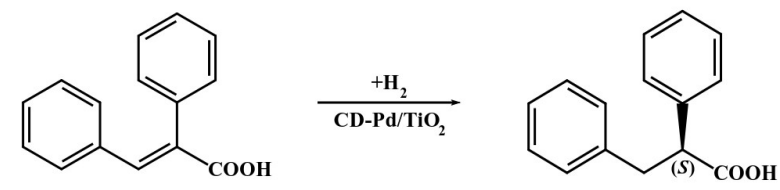

ee $72 \%$

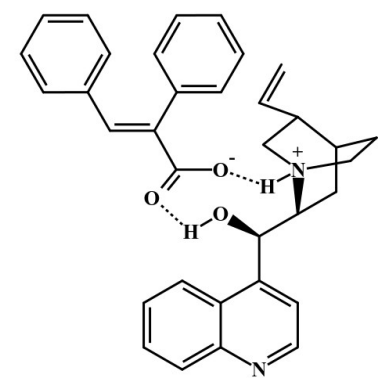

Scheme 6

Hydrogenation of $(E)$-2,3-diphenylpropenoic acid over a Pd catalyst in the presence of $\mathrm{CD}$, and the structure of the suggested intermediate complex

This result was obtained under the following conditions: reduced temperature $(273 \mathrm{~K})$, low $\mathrm{H}_{2}$ pressure $(1 \mathrm{~atm})$, and a low unsaturated acid/CD ratio in $N, N$-dimethylformamide-water solvent mixture. The results demonstrated that a high ee can be achieved with a catalyst of $\mathrm{Pd} / \mathrm{TiO}_{2}$ containing $3-10 \%$ metal with a $\mathrm{Pd}$ dispersion of $0.2-0.35$, prepared by a precipitation method $[62,64]$. Additionally, the structure of the support proved to be important. The ee decreased when porous supports were used, as the metal particles located in the pores of the support facilitated racemic hydrogenation [61,62].

The enantioselectivity increased when the solvent polarity was increased [57]; the highest optically purity was obtained with solvents containing $2.5-10$ vol.\% water $[57,65]$. Increase of the $\mathrm{H}_{2}$ pressure led to lower ee-s, due to the increase of the reaction rate on unmodified centres [63]. Similarly, an increase in ee was observed on decrease of the reaction temperature, which also had a marked effect on the reaction rate [58]. In contrast with the hydrogenation of $\alpha$-keto esters over a CD-Pt catalyst, in this case the hydrogenation rate decreased in the presence of the modifier, due to the decrease in the active metal surface. A relatively large amount of the modifier (at least $3 \mathrm{~mol} \%$ ) was necessary to provide the highest ee [58]. The structure of the surface intermediate was deduced from the alterations in the structure of the cinchona alkaloid [60]. Since the direction of the enantioselectivity was changed by using $\mathrm{CN}$ as compared with $\mathrm{CD}$, it became obvious that the $\mathrm{C}_{8}$ and the $\mathrm{C}_{9}$ stereogenic centres of the alkaloids are responsible for the chiral induction. The low ee obtained with $\mathrm{CN}$ suggests that the strong adsorption of the cinchona and steric effects play 
important roles in the modifier-acid interaction. This was also indicated by the extremely low ee values observed with QN and QD. The low ee-s obtained on the use of CD methyl ether can be explained in that the acid not only protonated the quinuclidine $\mathrm{N}$, but also interacted with the $\mathrm{C}_{9}-\mathrm{OH}$ via $\mathrm{H}$-bonding. The modifier-acid interaction suggested according to these results is presented in Scheme 6.

The application of achiral amine additives led pronounced increases in ee and the reaction rate $[65,66]$. The use of $0.5-1$ equivalent of benzylamine (BA) proved most effective. The dual effect of BA on ee and the reaction rate indicated that the increase in the latter occurred selectively on the modified chiral centres. The results were explained in terms of promotion of the desorption of the saturated products from modified sites (i.e. interaction with the cinchona) in the presence of the amine. Accordingly, the rate-determining step differs over the unmodified and the modified surface sites; in the latter case, the desorption of the product is relevant [66].

The promising results obtained in the hydrogenation of $(E)$-2,3-diphenylpropenoic acid in the presence of $\mathrm{CD}$ accelerated the search for more efficient modifiers, but the CD-Pd system proved best [67]. On the other hand, studies of the hydrogenations of other carboxylic acids were also initiated. From studies of the hydrogenation of (E)-2-methyl-3phenylpropenoic acid, it was concluded that the orientation of the acid on the surface is determined by the structure of the $\beta$ substituent, while ee is influenced by both the $\alpha$ and the $\beta$ substituent [68]. The study of the hydrogenation of indenecarboxylic acids revealed that ee is decreased by isomerization of the $\mathrm{C}=\mathrm{C}$ bond: in the hydrogenation of 3-methylindene-2carboxylic acid, an optical purity of only $45 \%$ was observed [69].

Nitta et al. recently obtained excellent ee-s in the hydrogenation of para-methoxysusbtituted (E)-2,3-diphenylpropenoic acid. The increased ee-s relative to the unsubstituted acid were explained by the electron-releasing effect of the substituent, which led to stronger interaction between the modifier and the unsaturated acid [70]. A para-methoxy group on both the $\alpha$ - and the $\beta$-phenyl ring increased ee, and the effect was additive, the highest ee values being obtained in the hydrogenations of para,para-dimethoxy-substituted compounds [70]. Use of an appropriate $\mathrm{Pd} / \mathrm{C}$ catalyst pretreated at $353 \mathrm{~K}$ in $\mathrm{H}_{2}$ in situ led to the highest ee up to that time (92\%) [71]. 


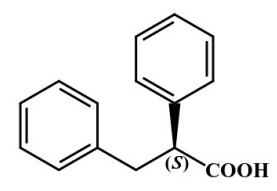

CD-Pd/TiO: ee $68 \%$ CD-Pd/C: ee $81 \%$<smiles>COc1ccc(C[C@H](C(=O)O)c2ccccc2)cc1</smiles>

$\mathrm{CD}-\mathrm{Pd} / \mathrm{TiO}_{2}$ : ee $80 \%$<smiles>CC(C)[C@H](Cc1ccccc1)C(=O)O</smiles>

CD-Pd/C: ee $80 \%$

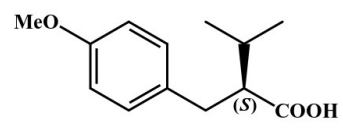

CD-Pd/C: ee $86 \%$<smiles>COc1ccc(C(Cc2ccccc2)C(=O)O)cc1</smiles>

CD-Pd/TiO<smiles>COc1ccc(CC(OC)C2CCCCC2)cc1</smiles>

CD-Pd/C: ee $81 \%$<smiles>COc1ccc(C[C@H](C(=O)O)c2ccc(OC)cc2)cc1</smiles>

CD-Pd/TiO : ee $82 \%$ CD-Pd/C: ee $92 \%$

Scheme 7

Saturated carboxylic acids obtained in high optical purities

The investigations were extended to the hydrogenations of (E)-2-alkyl-3-phenylpropenoic acids and their para-methoxy derivatives. In the case of branched $\alpha$-alkyl-substituted acids, the products were obtained in high optical purities (Scheme 7) [72], which was in accordance with the suggestion explaining the effects of the substituents on ee and the orientation of the acid on the surface [68].

\subsubsection{Hydrogenations of aliphatic unsaturated carboxylic acids over Pd catalysts modified} with cinchona alkaloids

The hydrogenations of the aliphatic prochiral $\alpha, \beta$-unsaturated carboxylic acids over Pd modified by cinchona alkaloids were examined simultaneously with the substituted cinnamic acids. Low ee was obtained over a $1 \% \mathrm{Pd} / \mathrm{SiO}_{2}$ catalyst [73], whereas the hydrogenation of (E)-2-methyl-2-pentenoic acid over commercial a $5 \% \mathrm{Pd} / \mathrm{Al}_{2} \mathrm{O}_{3}$ catalyst in the presence of CD yielded (S)-2-methylpentanoic acid in higher optical purity (Scheme 8) [74].

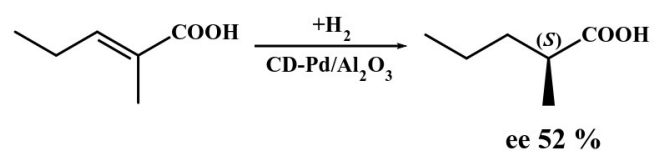

\section{Scheme 8}

Enantioselective hydrogenation of $(E)$-2-methyl-2-pentenoic acid 
Further examinations were planned to extend the applicability of the catalytic system, to increase ee and to examine the structure of the surface intermediate complex responsible for ee since it was known that these acids exhibit different behaviour as compared with the acids bearing aromatic substituents $[63,64,68,74-81]$. The results indicated that ee increases when high pressure and non-polar solvents are used: the best results were achieved at 50-60 bar $\mathrm{H}_{2}$ pressure in an apolar solvent $[74,80] .5 \% \mathrm{Pd} / \mathrm{Al}_{2} \mathrm{O}_{3}$ with a $\mathrm{Pd}$ dispersion of $0.2 \mathrm{Pd}$ and a mean particle diameter, of $5-7 \mathrm{~mm}$ pretreated at $295 \mathrm{~K}$ in situ, proved to be the most efficient catalyst $[76,78]$. The extremely large surface acidity of this catalyst led to the suggestion, that the support may also participate in the formation of the surface intermediate [81].

It was proved that the structure of the carboxylic acid has an important effect on ee. The enantioselectivity increased when compounds with a longer alkyl chain in the $\beta$ position were used $[68,75]$; additionally, the orientation of the acids on the surface was the opposite of that observed in the reactions of the $\alpha$-substituted cinnamic acids [68]. Hydrogenation of the $Z$ isomers led to much lower ee-s than for the $E$ isomers: the lowest ee was obtained with compounds containing terminal double bonds (Scheme 9) $[68,75]$. It was demonstrated that, in parallel with the hydrogenation, isomerization involving a double bond shift occurs, which may be responsible for the lower ee-s in comparison with the hydrogenation of (E)-2,3diphenylpropenoic acids, when such isomerization is not possible [77].

Deuteration experiments also confirmed that isomerization takes place and demonstrated that in the presence of $\mathrm{CD}$ this secondary reaction is inhibited by the use of high $\mathrm{H}_{2}$ pressure [79]. Attempts to increase ee showed that utilization of a large amount of $\mathrm{CD}$, a decreased temperature and pretreatment of the catalyst with ultrasound [78] may lead to slightly better results. It was recently demonstrated that ee can be increased by using BA as additive in the reactions of aliphatic acids, too [82]. A further increase resulted from the use of optically pure $(R)$-1-phenylethylamine instead of BA.

The effect of the modifier structure on ee was similar to that experienced in the hydrogenation of (E)-2,3-diphenylpropenoic acid [76,78]. The use of CD C9-ethers [78], $\mathrm{N}$-methylcinchonidinium salt and 9-deoxy-CD [76] proved that the free $\mathrm{C}_{9}-\mathrm{OH}$, the quinuclidine nitrogen and the $\mathrm{C}_{9}$ chiral centre are necessary for enantioselective hydrogenation. The influence of the reaction conditions on ee and the reaction rate and the spectroscopic and quantum chemical modelling results suggested the presence of a cyclic intermediate complex $[83,84]$. 


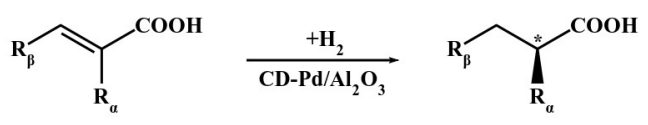

\begin{tabular}{cllr}
$\mathbf{R}_{\boldsymbol{\alpha}}$ & $\mathbf{R}_{\boldsymbol{\beta}}$ & \multicolumn{1}{c}{ Additive } & ee \\
$\mathrm{Et}, \mathrm{Pr}$ & $\mathrm{H}$ & - & $20 \%$ \\
$\mathrm{Et}$ & $\mathrm{H}$ & Benzylamine & $24 \%$ \\
$\mathrm{Me}$ & $\mathrm{Me}$ & - & $48 \%$ \\
$\mathrm{Me}$ & $\mathrm{Me}$ & Benzylamine & $58 \%$ \\
$\mathrm{Me}$ & $\mathrm{Me}$ & $(R)-1$-phenylethylamine \\
$\mathrm{Me}$ & $\mathrm{Et}$ & - & $63 \%$ \\
$\mathrm{Me}$ & $\mathrm{Et}$ & Benzylamine & $53 \%$ \\
$\mathrm{Me}$ & $\mathrm{Et}$ & $(R)-1-$ phenylethylamine \\
$\mathrm{Me}$ & $\mathrm{Et}$ & Pretreatm. with ultrasonic & $61 \%$ \\
$\mathrm{Me}$ & $\mathrm{Pr}$ & - & $63 \%$ \\
$\mathrm{Me}$ & $\mathrm{Pr}$ & $(R)-1$-phenylethylamine & $66 \%$ \\
$\mathrm{Et}$ & $\mathrm{Pr}$ & - & $56 \%$ \\
$\mathrm{Et}$ & $\mathrm{Pr}$ & $(R)-1$-phenylethylamine & $63 \%$ \\
& & & $55 \%$ \\
& & $61 \%$
\end{tabular}

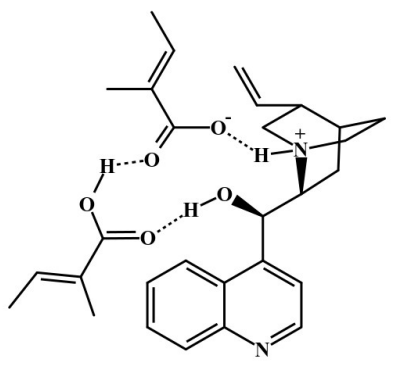

Scheme 9

Enantioselective hydrogenations of aliphatic unsaturated carboxylic acids and the suggested structure of the intermediate complex

To establish the structure of this, the stabilitier of the different CD conformers [85] and their behaviour on the Pd surface [86,87], the ability of carboxylic acids to undergo dimerization [88] and the effects of amines on the monomer-dimer equilibrium [89] were considered. It was concluded from that $\mathrm{CD}$ interacts with the carboxylic acid dimer, forming two H-bonds via the $\mathrm{C}_{9}-\mathrm{OH}$ group and the protonated quinuclidine $\mathrm{N}$ in the intermediate complex (Scheme 9) $[76,84]$. Although formation of this cyclic 1:2 intermediate complex is widely accepted, complexes with 1:1 compositions have also been suggested [80]. The exact role of BA in this reaction is still unknown, and its exploration may lead to refinement of the structure of the intermediate complex responsible for the enantiodifferentiation on the surface. 


\subsubsection{Hydrogenations of unsaturated dicarboxylic acids over cinchona-modified Pd catalysts}

The enantioselective hydrogenations of prochiral $\alpha, \beta$-unsaturated dicarboxylic acids are a test reactions often used in the investigation of chiral metal complexes [19], but significant results have also been achieved recently over a chirally modified heterogeneous catalyst [82]. The hydrogenations of citraconic, mesaconic and itaconic acid resulted in low ee values over CD-Pd. However, a noteworthy increase in ee was experienced in the hydrogenation of itaconic acid with BA as additive (up to 58\%) (Scheme 10) [82,90]. The detailed investigations of this reaction indicated that the considerable increase in ee was due to the multiple effect of BA. Variations observed in the reaction rate when the reaction components were added in a different sequence or the BA/itaconic acid ratio was changed showed that the amine adsorbed on the surface partially hinders racemic hydrogenation, especially at low $\mathrm{H}_{2}$ pressure. On the other hand, when 2 equivalents of BA are used, the bis-ammonium salt is formed, and the unsaturated acid therefore does not interact with the $\mathrm{CD}$ via its more acidic carboxylic group, distant from the $\mathrm{C}=\mathrm{C}$ double bond, but via the more basic conjugated carboxylate anion [90]. This conclusion was confirmed by the results obtained in the reactions of itaconic acid half-esters. The structure of the intermediate complex is still unknown, but it is probable that CD interacts with one molecule of the acid on the surface. The participation of $\mathrm{BA}$ in the formation of the surface complex is ambiguous and necessitates further examinations.

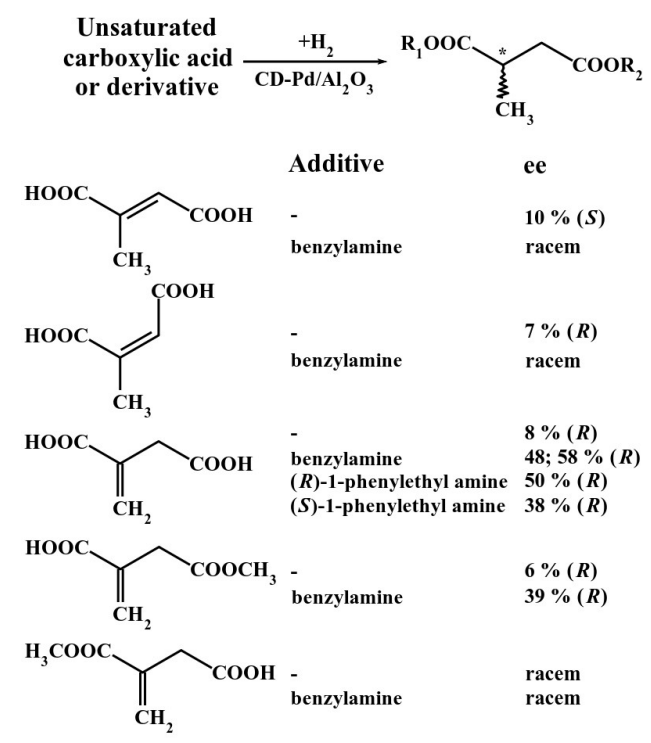

Scheme 10

Hydrogenations of dicarboxylic acids and their derivatives over a CD-Pd/ $\mathrm{Al}_{2} \mathrm{O}_{3}$ catalyst 


\subsubsection{Hydrogenations of heteroaromatic carboxylic acids over cinchona-modified Pd}

catalysts

The attachment of chiral groups to aromatic compounds and diastereoselective hydrogenation of these intermediates is a known method for the enantioselective saturation of aromatic rings [91,92]. Direct enantioselective catalytic hydrogenation of an aromatic ring appears simpler than the above-mentioned method, though this proved successful only in the hydrogenation of furancarboxylic acids over a Pd catalyst in the presence of CD (Scheme 11) [93-95]. Whereas high ee-s could be achieved in the hydrogenations of furan-2-carboxylic acid and benzofuran-2-carboxylic acid, the yields were low and the hydrogenation of the modifier $[96,97]$ led to a decrease in ee, due to the slow reaction. Thus, continuous addition of $\mathrm{CD}$ to the reaction mixture was necessary [93]. Spectroscopic examinations, quantum chemical modelling of the modifier-acid interaction [94] and the effects of the structure of strong acid additives and modifiers [95] point to the presumed structure of the intermediate complex being similar to that of an aliphatic unsaturated carboxylic acid, i.e. an intermediate with a cyclic $\mathrm{CD}$ /acid 1:2-type interaction is suggested.

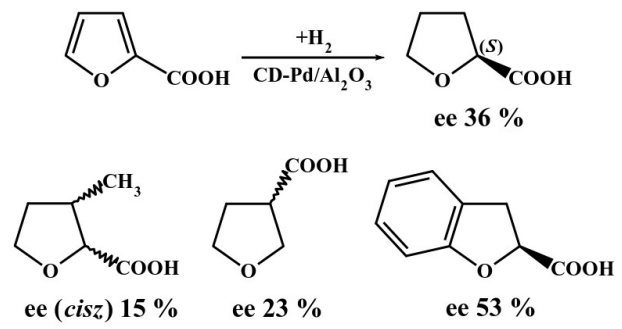

\section{Scheme 11}

Enantioselective hydrogenations of furancarboxylic acids

\subsubsection{Hydrogenations of dehydroamino acid derivatives and unsaturated carboxylic acids} containing a trifluoromethyl group

A simple and economic method for the preparation of optically pure aminoacids is heterogeneous catalytic enantioselective hydrogenation of the corresponding dehydroamino acids. Chirally modified metal catalysts have been tested in the hydrogenation of $N$-acyldehydroamino acids and their esters [98-102]. The best results were obtained in the hydrogenations of $N$-benzoylcyclohexylglycine and $N$-benzoyl-3',4'-dibenzyloxydehydrophenylalanine (ee $=26 \%$ and $40 \%$ ) over a $\mathrm{Pd} / \mathrm{C}$ catalyst (Scheme 12) $[101,102]$. The 
promising results obtained in the presence of BA in the hydrogenations of other unsaturated acids led to hydrogenations of two $\alpha$-acetamido- $\alpha, \beta$-unsaturated carboxylic acids also being examined [103].

In the case of $\mathrm{N}$-acetyldehydrophenylalanine, the ee observed was low and did not increase significantly on the addition of BA. Interestingly, increase of the $\mathrm{H}_{2}$ pressure resulted in the inversion of ee. These results gave rise to the assumption, that the presence of both the $\alpha$-amide and the $\beta$-phenyl group contributed to the processes leading to inversion. In the hydrogenation of $\mathrm{N}$-acetyldehydroalanine, containing a terminal $\mathrm{C}=\mathrm{C}$ group, ee was significantly increased over CD-Pd in the presence of BA, similarly as for the hydrogenation of itaconic acid. In contrast with the hydrogenations of unsaturated carboxylic acids, when $\mathrm{CN}$ was used as modifier, the optical purity exceeded that obtained with CD (Scheme 12) [103]. The hydrogenation of this compound is influenced in the same way as for itaconic acid by the presence of BA as additive, i.e. BA is attached to the surface of the catalyst and interacts with the acid resulting in the formation of the corresponding salt. Optically pure amino acids can also be produced by enantioselective hydrogenation of the corresponding prochiral unsaturated imines. However, low ee-s were obtained in the hydrogenations of pyruvic acid oxime or dehydroproline and its derivatives over a Pd catalyst in the presence of cinchona alkaloids [104,105].

With regard to the special properties of fluorinated compounds, several methods have been elaborated for the preparation of optically pure fluorinated chiral intermediates [106,107], including enantioselective hydrogenations of fluorinated prochiral compounds [108]. Excellent ee-s were obtained in the hydrogenations of fluoroketones over a CD-Pt catalyst in several cases [109-111], but there are only a few literature examples of enantioselective hydrogenations of unsaturated fluoro carboxylic acids over heterogeneous catalysts. The reaction of (E)-2-methyl-4,4,4-trifluoro-2-butenoic acid led to low ee-s over CD-Pd (Scheme 13) [73]. Similar results were achieved in the hydrogenations of 2trifluoromethylacrylic acid and 3-trifluoromethyl-2-butenoic acid [112]. In the reaction of the latter compound, $(R)$-3-trifluoromethylbutanoic acid was prepared with medium ee in the presence of BA. 
<smiles>[Y]C=C(NC(=O)CC)C(=O)O</smiles>

CD: ee $26 \%$<smiles>O=C(N[C@@H](Cc1ccc(O)c(O)c1)C(=O)O)c1ccccc1</smiles>

CN: ee $40 \%$

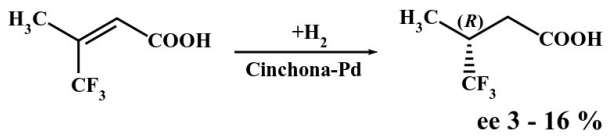

$$
\begin{aligned}
& \text { with BA ee } 42,43 \%
\end{aligned}
$$

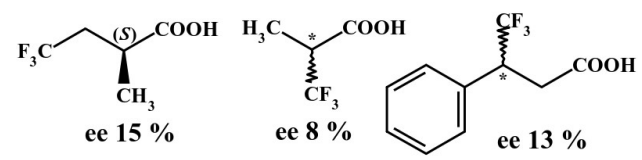

\section{Scheme 12}

Enantioselective hydrogenations of dehydroamino acid derivatives over cinchona-modified Pd catalysts

Almost identical optical purities were attained in methanol over $\mathrm{Pd} / \mathrm{Al} 2 \mathrm{O} 3$ or in toluene over $\mathrm{Pd} / \mathrm{TiO} 2$. Low ee was also obtained in the hydrogenation of 3-trifluoromethylcinnamic acid. This was the first example of the enantioselective hydrogenation of an unsaturated carboxylic acid with the chiral centre in the b position (Scheme 13) [112].<smiles>CC(=O)NC(Cc1ccccc1)C(=O)O</smiles>

CD:

$1 \mathrm{~atm} \mathrm{H}_{2}$ ee $36 \%(R)$

$50 \operatorname{atm~H_{2}}$ ee $5 \%(S)$

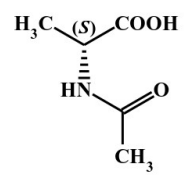

CD: ee $9 \%$ with BA: ee $58 \%$<smiles>CC(=O)N[C@@H](C)C(=O)O</smiles>

CN: ee $3 \%$ with BA: ee $60 \%$

\section{Scheme 13}

Hydrogenations of $\alpha, \beta$-unsaturated carboxylic acids containing a trifluoromethyl group over cinchona-modified Pd catalysts 


\subsection{Hydrogenation in a continuous-flow system}

A further advantage of heterogeneous catalytic systems is their easy applicability in continuous processes. The first studies on the Orito reaction in a continuous-flow system were reported by Wells et al., who studied the enantioselective hydrogenation of methyl pyruvate [113], and by Baiker et al., on the reaction of ethyl pyruvate and ketopantolactone [114] in a continuous-flow system. While the hydrogenation of $\alpha$-ketoesters was successful in continuous systems over a Pt catalyst [114], in the enantioselective hydrogenations of prochiral olefins over a modified $\mathrm{Pd}$ catalyst, good ee-s were reported only in the hydrogenations of 2-pyrone derivatives, though accompanied by low yields [115].

\subsection{Studies published during or following our investigations}

In parallel with our own studies on the enantioselective hydrogenations of substituted (E)-2,3-diphenylpropenoic acids, several reports were published on the reactions of the same or similar compounds. Moreover, the catalytic system, including the catalyst, the reaction conditions, the substrate scope and the modifier structure, was continuously developed. The most important developments are surveyed in this subsection.

The effects of the catalyst support, the reaction temperature and the concentration of the modifier were investigated with the aim of obtaining higher ee in the hydrogenation of $(E)$ 2,3-diphenylpropenoic acid. An ee $>90 \%$ was achieved by using a CD-modified $40 \mathrm{wt} \%$ $\mathrm{Pd} / \mathrm{TiO}_{2}$ catalyst at $288 \mathrm{~K}$ and $\mathrm{BA}$ as additive. Ee increased with the Pd loading and hence with the size of the Pd metal particles, suggesting that the selective hydrogenation takes place on a low-index plane of the Pd particles modified by a self-assembled CD ad-layer [116].

The relationship between the substrate structure and ee was studied in the asymmetric hydrogenations of $(E)$-2,3-diphenylpropenoic acid derivatives over a $\mathrm{CD}$-modified $\mathrm{Pd} / \mathrm{C}$ catalyst. It emerged that $\alpha, \beta$-unsaturated acids with an appropriately bulky $\alpha$ substituent and an electron-donating $\beta$-aryl group are suitable substrates for enantioselective hydrogenation. High ee (up to 92\%) was achieved on $\beta$-para-alkoxyphenyl substitution, which was ascribed mainly to the stronger interaction of the substrate with the chiral modifier on the catalyst surface [117].

The low ee-s observed when two regioisomeric $\alpha$-phenyl- $\beta$-pyridylacrylic acids were hydrogenated were attributed to the strong adsorption of the substrate. It was indicated that strongly adsorbed substrates are not suitable for enantioselective hydrogenation due to their 
competition with the $\mathrm{CD}$ adsorbed on the surface. Ee was improved up to $82 \%$ at a low substrate/CD ratio for $(E)$ - $\alpha$-phenyl- $\beta$-(4-pyridyl)acrylic acid, and to $45 \%$ for $(E)$ - $\alpha$-phenyl- $\beta$ (3-pyridyl)acrylic acid. The difference between the isomers suggests that strong adsorption of the substrate on the metal surface may interrupt the interaction between CD and the substrate. The degrees of adsorption of (E)-2,3-diphenylpropenoic acid and (E)-2-(4-methoxyphenyl)-3(4-methoxyphenyl)propenoic acid are much weaker than those of the two regioisomeric $\alpha$-phenyl- $\beta$-pyridylacrylic acids, and the higher ee for (E)-2-(4-methoxyphenyl)-3-(4methoxyphenyl)propenoic acid may also be attributable to its weaker competition with the adsorbed CD [118].

Sugimura et al. showed that asymmetric heterogeneous hydrogenation can be performed in water, and an even higher ee may be observed in water as compared with an organic solvent. The $\mathrm{Pd} / \mathrm{C}$ was admixed with a small amount of a hydrophobic water-immiscible organic solvent. The catalyst surface was kept hydrophobic, while the substrate and product were transferred between the aqueous layer and the lipophilic droplets containing the catalyst. Thus, the product was readily removed by separation of the aqueous phase under a $\mathrm{H}_{2}$ atmosphere, and the remaining catalyst could be reused [119].

The performances of $\mathrm{CD}$ and $\mathrm{CN}$ were compared as chiral modifiers in enantioselective hydrogenations over $\mathrm{Pd} / \mathrm{C}$. The hydrogenation with $\mathrm{CD}$ always proceeded with better ee and at a higher rate than that with $\mathrm{CN}$. The difference is due not to the adsorption properties, but to the intrinsic stereocontrollability and the acceleration effect, both of which originate from the interaction between the modifier and substrate [120].

The structure of the CD-unsaturated acid intermediate complex has not been determined exactly, but some suggestions have been proposed on the basis of the recent studies mentioned above. The intermediate complexes postulated to be formed in the presence of BA during the hydrogenations of (E)-2.3-diphenylpropenoic acids are presented in Scheme 14.
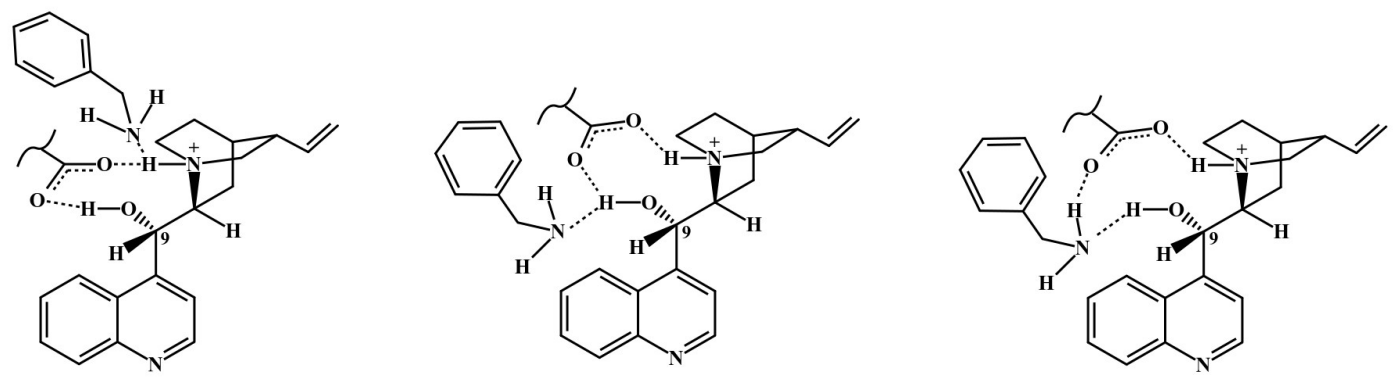

Scheme 14

Proposed structures of the modifier-acid complexes in the presence of BA 


\section{RESULTS AND DISCUSSION}

\subsection{Hydrogenations of unsaturated $\alpha, \beta$-carboxylic acids in a batch reactor}

\subsubsection{Preparation of the unsaturated $\alpha, \beta$-carboxylic acids}

Our aim was to study the effects of the nature and positions of the substituents on the $\alpha$ and $\beta$-phenyl rings of $(E)$-2,3-diphenylpropenoic acid on their enantioselective hydrogenation over a CD-modified Pd catalyst. We, therefore initially prepared the unsaturated acids chosen for these studies. These acids included methoxy-, fluoro- and methyl-mono- and disubstituted compound, bearing the substituents in different positions.

The substituted 2,3-diphenylpropenoic acid derivatives were prepared by Perkin condensation according to the Fieser method [121-123], using the corresponding aromatic aldehydes and arylacetic acids purchased from Fluka or Aldrich (Scheme 15).

A stirred mixture of arylacetic acid and aromatic aldehyde in triethylamine and acetic anhydride was refluxed for 4-6 h. Concentrated $\mathrm{HCl}$ and water were added to the cooled mixture and the resultant precipitate was filtered off and washed with cold water. After drying, the solid was dissolved in $1 \%$ aqueous $\mathrm{NaOH}$ solution, and the alkaline solution was stirred with charcoal at room temperature and filtered. For the separation of the $E$ and $Z$ isomers, the alkaline solution was gradually acidified with $1: 1$ conc. $\mathrm{HCl} /$ water solution. When the reaction product after acidification was a semi-solid or an oil, it was dissolved in diethyl ether. The ethereal solution was then extracted with $1 \% \mathrm{NaOH}$ solution and the alkaline solution was treated as above. The isomeric acids were further purified by crystallization in ethanol or ethanol-water.

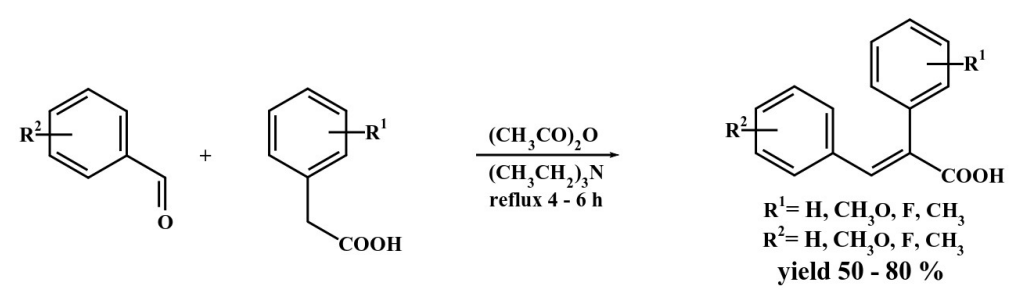

Scheme 15

Preparation of substituted (E)-2,3-diphenylpropenoic acid derivatives 
The isomeric distribution of the crude reaction products and the purities of the prepared acids were monitored by analytical TLC (Fluka Silica gel/TLC cards, eluent hexane/acetone 5:3) and GC-MS analysis (as methyl esters prepared through the use of ethereal $\mathrm{CH}_{2} \mathrm{~N}_{2}$ solution, GC-MS: Agilent Techn. 6890N GC-5973 MSD, HP-1MS, $60 \mathrm{~m}$ capillary column). The purities of the acids were checked by melting point measurements and by recording their ${ }^{1} \mathrm{H}$ and ${ }^{13} \mathrm{C}$ NMR spectra in $\left(\mathrm{CD}_{3}\right)_{2} \mathrm{SO}$ solution on a Bruker Avance DRX 500 NMR instrument $\left({ }^{1} \mathrm{H}\right.$ at $500 \mathrm{MHz},{ }^{13} \mathrm{C}$ at $\left.125 \mathrm{MHz}\right)$. Their purities were $>98 \%$. The $E$ isomers were prepared in $50-80 \%$ yields, whereas the $Z$ isomers were obtained in low yields and were not always purified. The structures of the investigated compounds are presented in Scheme 16.
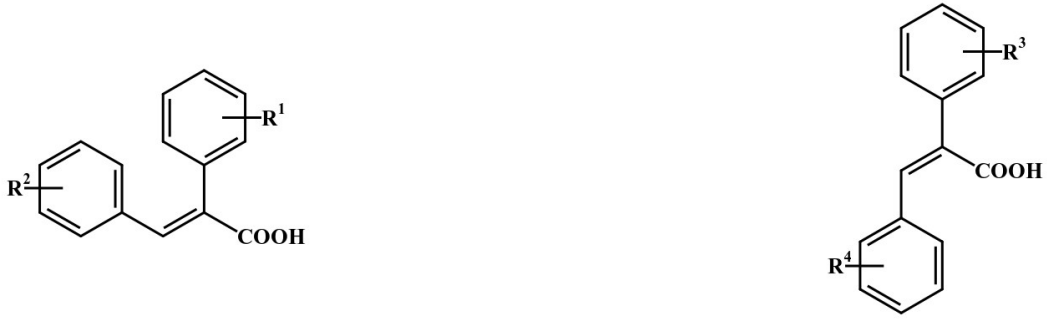

\begin{tabular}{|c|c|c|c|c|c|c|c|c|c|c|c|c|c|c|}
\hline & $\mathbf{R}^{1}$ & $\mathbf{R}^{2}$ & & $\mathbf{R}^{1}$ & $\mathbf{R}^{2}$ & & $\mathbf{R}^{1}$ & $\mathbf{R}^{2}$ & & $\mathbf{R}^{1}$ & $\mathbf{R}^{2}$ & & $\mathbf{R}^{3}$ & $\mathbf{R}^{4}$ \\
\hline 1 & $\mathrm{H}$ & $\mathrm{H}$ & 16 & $\mathrm{H}$ & 4-F & 26 & $4-F$ & $4-\mathrm{F}$ & 31 & $\mathrm{H}$ & 4-Me & 13 & 4-MeO & $\mathrm{H}$ \\
\hline 2 & $2-\mathrm{MeO}$ & $\mathrm{H}$ & 17 & $\mathrm{H}$ & $2-F$ & 27 & $4-F$ & $3-\mathrm{F}$ & 32 & 2-Me & $\mathrm{H}$ & 14 & 4-MeO & 3-MeO \\
\hline 3 & 3-MeO & $\mathrm{H}$ & 18 & $2-F$ & $\mathrm{H}$ & 28 & $4-F$ & $2-F$ & 33 & 2-Me & 4-Me & 15 & 4-MeO & 4-MeO \\
\hline 4 & 4-MeO & $\mathrm{H}$ & 19 & 4-MeO & 4-F & 29 & $2-F$ & $4-F$ & 34 & $2-\mathrm{Me}$ & $4-\mathrm{F}$ & & & \\
\hline 5 & $\mathrm{H}$ & $4-\mathrm{MeO}$ & 20 & $4-F$ & 4-MeO & 30 & $2-F$ & $3-F$ & 35 & $2-\mathrm{F}$ & 4-Me & & & \\
\hline 6 & $\mathrm{H}$ & $3-\mathrm{MeO}$ & 21 & 4-F & $2-\mathrm{MeO}$ & & & & 36 & 2-MeO & 4-Me & & & \\
\hline 7 & $\mathrm{H}$ & $2-\mathrm{MeO}$ & 22 & $2-\mathrm{F}$ & 4-MeO & & & & & & & & & \\
\hline 8 & $2-\mathrm{MeO}$ & $4-\mathrm{MeO}$ & 23 & 2-MeO & 4-F & & & & & & & & & \\
\hline 9 & 3-MeO & $3-\mathrm{MeO}$ & 24 & $2-\mathrm{MeO}$ & $3-F$ & & & & & & & & & \\
\hline 10 & 4- $\mathrm{MeO}$ & $2-\mathrm{MeO}$ & 25 & 2-MeO & $2-\mathrm{F}$ & & & & & & & & & \\
\hline 11 & 4- $\mathrm{MeO}$ & $3-\mathrm{MeO}$ & & & & & & & & & & & & \\
\hline 12 & $4-\mathrm{MeO}$ & $4-\mathrm{MeO}$ & & & & & & & & & & & & \\
\hline
\end{tabular}

Scheme 16

Structures of the $(E)$ - and (Z)-2,3-diphenylpropenoic acid derivatives prepared 


\subsubsection{Choice of the corresponding solvent and catalyst}

The hydrogenation of $(E)$-2,3-diphenylpropenoic acid in the presence of CD resulted in excess formation of $(S)$-2,3-diphenylpropionic acid, as presented in Scheme 17.

It has become well known that, in the enantioselective hydrogenation of this unsaturated acid, the highest optical purities are obtained by using low $\mathrm{H}_{2}$ pressure and low reaction temperature in polar solvents containing small amounts of water, such as DMF and 1,4dioxane [66]. Indeed, in our preliminary experiments on the hydrogenation of this unsaturated acid, the best ee was obtained in DMF containing 2.5 vol. $\% \mathrm{H}_{2} \mathrm{O}$; both methanol and 1,4dioxane containing 2.5 vol. $\% \mathrm{H}_{2} \mathrm{O}$ gave lower ee-s.

The proper choice of the catalyst also exerts a crucial influence on the outcome of these hydrogenations. Besides the metal dispersion [62,64], the textural properties of the support have a significant effect on the enantioselectivity $[61,62]$. It was found that good ee values were obtained over Pd deposited on the outer surface of the supports or by using non-porous supports. Thus, we tested several catalysts in the hydrogenation of (E)-2-(2-methoxyphenyl)3-phenylpropenoic acid (2); selected results are presented in Table 1.

As expected, the initial hydrogenation rates decreased significantly over the modified catalysts as compared with the racemic reactions. The ratio of the initial reaction rates on unmodified $\left(r_{u}\right)$ and modified $\left(r_{m}\right)$ catalysts correlated well with the ee-s obtained; the lowest $r_{u} / r_{m}$ value and the best ee were obtained over $5 \% \mathrm{Pd} / \mathrm{Al}_{2} \mathrm{O}_{3}$ having a B.E.T. surface area of $185-200 \mathrm{~m}^{2} \mathrm{~g}^{-1}$ and a Pd dispersion of 0.19-0.21 [76,81].
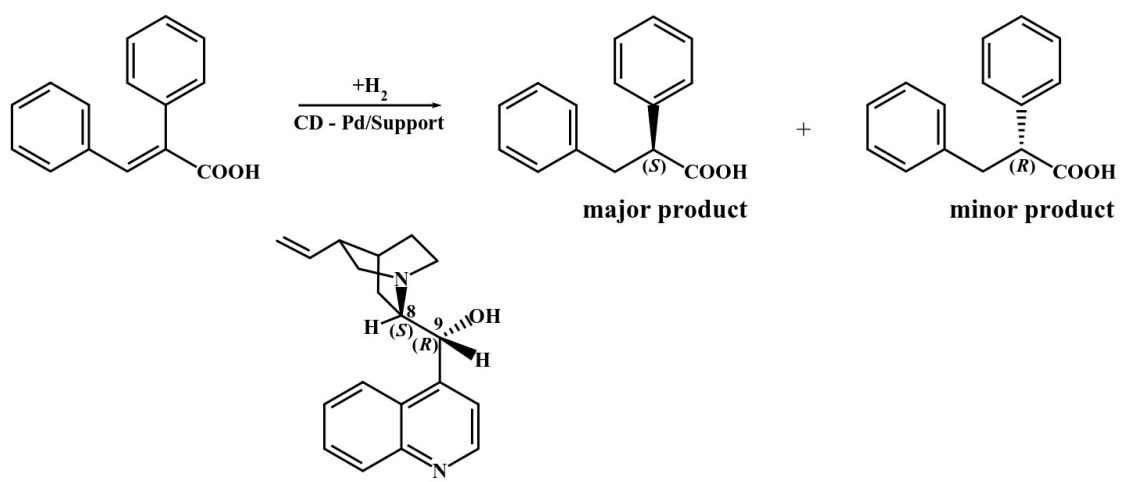

major product

minor product

CD

Scheme 17

Enantioselective hydrogenation of (E)-2,3-diphenylpropenoic acid over a supported Pd catalyst in the presence of CD 
Table 1

Hydrogenation of $\mathbf{2}$ over supported Pd catalysts

\begin{tabular}{lccllll}
\hline Catalyst & $\mathrm{r}_{\mathrm{u}}{ }^{\mathrm{a}}$ & $\mathrm{r}_{\mathrm{m}}{ }^{\mathrm{a}}$ & $\mathrm{r}_{\mathrm{u}} / \mathrm{r}_{\mathrm{m}}$ & $\mathrm{r}_{\mathrm{BA}}{ }^{\mathrm{b}}$ & ee $(\%)$ & $\mathrm{ee}_{\mathrm{BA}}{ }^{\mathrm{b}}(\%)$ \\
\hline $5 \% \mathrm{Pd} / \mathrm{TiO}_{2}$ & 24.4 & 3.2 & 7.6 & 15.1 & 69 & 77 \\
$5 \% \mathrm{Pd} / \mathrm{C}$ & 61.7 & 4.9 & 12.6 & 20.3 & 42 & 67 \\
$10 \% \mathrm{Pd} / \mathrm{C}$ & 86.4 & 8.3 & 10.4 & 20.5 & 62 & 78 \\
$5 \% \mathrm{Pd} / \mathrm{Al}_{2} \mathrm{O}_{3}$ & 49.9 & 7.6 & 6.6 & $18.2 ; 16.3^{\mathrm{c}}$ & 72 & $80 ; 77^{\mathrm{c}}$ \\
$5 \% \mathrm{Pd} / \mathrm{Al}_{2} \mathrm{O}_{3}{ }^{\mathrm{P}, \mathrm{d}}$ & 22.9 & 5.7 & 4.0 & 11.1 & 76 & 85 \\
\hline
\end{tabular}

Reaction conditions: $25 \mathrm{mg}$ catalyst, $5 \mathrm{~cm}^{3} \mathrm{DMF}+2.5 \mathrm{vol} \% \mathrm{H}_{2} \mathrm{O}, 0.025 \mathrm{mmol} \mathrm{CD}, 0.5 \mathrm{mmol} 2,0.1 \mathrm{MPa} \mathrm{H}_{2}$, $294 \mathrm{~K}$, conversions $>98 \%$ in $2 \mathrm{~h}$ (unmodified) - $8 \mathrm{~h}$ (modified)

${ }^{a} r_{u}$ and $r_{m}$ are the initial rates $\left(\mathrm{mmol} \mathrm{h}^{-1} \mathrm{~g}^{-1}\right)$ obtained in the absence and the presence of CD.

${ }^{\mathrm{b}} \mathrm{r}_{\mathrm{BA}}$ and $\mathrm{e}_{\mathrm{BA}}$ are the initial rate and ee obtained on the addition of $0.5 \mathrm{mmol}$ (1 equivalent) BA.

${ }^{c}$ Values obtained by using $0.25 \mathrm{mmol}(0.5$ equivalent) BA as additive.

${ }^{\mathrm{d}}$ Catalyst pretreated in a $\mathrm{H}_{2}$ flow at $523 \mathrm{~K}$ for 100 min before use.

A further increase in ee was obtained by pretreating this catalyst. The commercial $5 \%$ $\mathrm{Pd} / \mathrm{Al}_{2} \mathrm{O}_{3}$ was used after the following pretreatment: $0.3 \mathrm{~g}$ catalyst was heated at $7.5 \mathrm{~K} \mathrm{~min}^{-1}$ to $523 \mathrm{~K}$ in $30 \mathrm{~cm}^{3} \mathrm{~min}^{-1} \mathrm{H}_{2}$, kept at this temperature for $100 \mathrm{~min}$, and then cooled to room temperature in $30 \mathrm{~min}$, which was followed by a $10 \mathrm{~min}$ flushing with He. The pretreated catalyst denoted as $\mathrm{Pd} / \mathrm{Al}_{2} \mathrm{O}_{3}{ }^{\mathrm{P}}$ was stored for no more than 5 days before use. Such pretreatment results in the removal of surface contamination, and a decrease in the $\mathrm{Pd}$ dispersion to some extent, due to sintering of the metal particles $[62,64]$ and migration of the metal from the pores to the external surface of the support. Indeed, both $r_{u}$ and $r_{m}$ decreased over the pretreated catalyst as a result of the decrease in the number of active sites. A more pronounced decrease in the rate was observed over the unmodified catalyst, leading to the lowest $\mathrm{r}_{\mathrm{u}} / \mathrm{r}_{\mathrm{m}}$ value and to an increased ee over $\mathrm{Pd} / \mathrm{Al}_{2} \mathrm{O}_{3}{ }^{\mathrm{P}}$.

Addition of $\mathrm{BA}$ to the reaction mixture increased both the initial rate $\left(\mathrm{r}_{\mathrm{BA}}\right)$ and ee. These increases in the presence of BA were attributed to the preferential acceleration of the reaction on modified sites through promotion of the desorption of the saturated product interacting with $\mathrm{CD}$ on the Pd surface [66]. Although the greatest ee increase in the presence of BA was obtained over the $5 \% \mathrm{Pd} / \mathrm{C}$ catalyst, the highest ee value $(85 \%)$ was observed over the pretreated $\mathrm{Pd} / \mathrm{Al}_{2} \mathrm{O}_{3}{ }^{\mathrm{P}}$. The enantioselectivity over a modified heterogeneous catalyst under certain experimental conditions is influenced by the fraction of the modified sites and by the intrinsic stereoselectivity of the modifier-substrate interaction on the surface $[35,70]$. The above results indicate that, of the catalysts used in this work, $\mathrm{Pd} / \mathrm{Al}_{2} \mathrm{O}_{3}{ }^{\mathrm{P}}$ has the highest ratio of modified surface metal sites. We subsequently used this catalyst in our investigations. A further increase in ee may be expected by improving the stereoselectivity of the modifier-acid 
interaction by modification of either the modifier or the unsaturated acid structure. This approach was used by Nitta et al. in their choice of examining the 4-methoxy derivatives [66]. In our work, we extended such investigations by studying the effects of the positions of the methoxy, fluoro and methyl substituents on both phenyl rings, using the compounds presented in Scheme 15.

\subsection{Hydrogenations of substituted 2,3-diphenylpropenoic acids}

\subsubsection{Hydrogenation procedure and product analysis}

The hydrogenations were carried out in batch reactors under atmospheric $\mathrm{H}_{2}$ pressure and room temperature (unless otherweise noted), in a glass hydrogenation apparatus, using magnetic stirring (1000 rpm). The $\mathrm{H}_{2}$ consumption up to $25 \%$ of the total $\mathrm{H}_{2}$ uptake was used to calculate the initial rates, taking into account the rapid hydrogenation of the vinyl group of CD. In a typical run, $0.025 \mathrm{~g}$ catalyst and $3 \mathrm{~cm}^{3}$ DMF containing 2.5 vol. $\% \mathrm{H}_{2} \mathrm{O}$ were introduced into the reactor, the apparatus was flushed with $\mathrm{H}_{2}$ and the catalyst was pretreated in situ by stirring for $0.5 \mathrm{~h}$. After pretreatment, $0.025 \mathrm{mmol}$ ( $5 \mathrm{~mol} \%$ ) CD, $0.5 \mathrm{mmol}$ unsaturated acid, $0.5 \mathrm{mmol} \mathrm{BA}$ (when used) and another $2 \mathrm{~cm}^{3}$ solvent were added, the system was flushed with $\mathrm{H}_{2}$ and the reaction was started by turning on the stirring. Unless otherwise noted, $>98 \%$ conversions were obtained in 1-4 h during hydrogenations in the absence of modifier, and in 6-8 h over modified catalysts.

After the $\mathrm{H}_{2}$ uptake had ceased, the precipitated products (when formed) were dissolved by the addition of $5 \mathrm{~cm}^{3}$ methanol, the catalyst was filtered off and washed with another two portions of solvent, and the combined filtrates were concentrated under reduced pressure. Small portions of these products were transformed into methyl esters by using concentrated $\mathrm{H}_{2} \mathrm{SO}_{4}$ in methanol or ethereal $\mathrm{CH}_{2} \mathrm{~N}_{2}$ solution. The resulting compounds were identified by GC-MS analysis. Conversions (X \%) and enantiomeric excesses (ee \%) were determined by GC analysis, using a HP 5890 II GC-FID and a 30 m chiral capillary column (Cyclosil-B). Ee was calculated via the formula ee $\%=100 \times|[S]-[R]| /([S]+[R])$, where $[S]$ and $[R]$ are the concentrations of the product enantiomers. When the separation of the methyl ester enantiomers was incomplete (few compounds), samples of the products were transformed into $(R)$-2-butyl and $(S)$-2-butyl esters, using $(R)$-2-butanol and $(S)$-2-butanol, respectively and ee was calculated after separation of the diastereomers on the same chiral capillary column. The ee values were reproducible within $\pm 1 \%$. 
The remaining products were taken up in $1 \mathrm{~cm}^{3} 10 \% \mathrm{HCl}$ solution and $9 \mathrm{~cm}^{3}$ water, the crude acids were extracted with three portions of $5 \mathrm{~cm}^{3} \mathrm{CHCl}_{3}$, the combined organic layers were dried over $\mathrm{Na}_{2} \mathrm{SO}_{4}$ and the solvent was evaporated to give the crude saturated acids in $>90 \%$ yields as pale-yellow oils or solids, and in $\geq 98 \%$ purity as determined by ${ }^{1} \mathrm{H}$ NMR spectroscopy and by GC analysis of the methyl esters obtained by using $\mathrm{CH}_{2} \mathrm{~N}_{2}$ in ethereal solution. The optical purities of these crude products were the same as determined for the corresponding samples analyzed before the work-up. The absolute configurations of the excess enantiomers of unsubstituted and 4-methoxy-substituted 2,3-diphenylpropenoic acids were assigned in previous studies to be $S[55,70]$. The configurations of the excess enantiomers resulting in the hydrogenation of the other compounds have not yet been determined, but the same rotation sign and similar chromatographic behaviour lead us to assume that the $S$ enantiomers were formed in excess. Optical rotation measurements with a Polamat A polarimeter showed that all these products contained the dextrorotatory enantiomers in excess.

\subsubsection{Hydrogenations of monomethoxy-or fluorine-substituted derivatives}

The results obtained in the hydrogenation of $\mathbf{1}$ and its monomethoxy derivatives are listed in Table 2. Substitution in the ortho position on the $\alpha$-phenyl ring led to a markedly higher ee as compared with the hydrogenation of 1; similarly, the 3-methoxy and especially the 4-methoxy substituent on the $\beta$-phenyl ring increased ee significantly. Surprisingly, a low ee was obtained in the reaction of 7 , in which the 2-methoxy substituent is on the $\beta$-phenyl ring. Thus, both ortho-substituted derivatives exhibited unusual behaviour: the 2-methoxy group on the $\alpha$-phenyl ring had a beneficial effect, while that on the $\beta$-phenyl ring had a detrimental effect on ee. It should be noted that, in the hydrogenation of $7, r_{u}$ decreased to only a small extent as compared with that in $\mathbf{1}$, while the lowest $r_{m}$ was obtained over the modified catalyst.

These results indicate that the 2-methoxy substituent on either the $\alpha$ - or the $\beta$-phenyl ring has a striking effect on the enantioselective hydrogenations of substituted 2,3-diphenylpropenoic acids. The 2-methoxy substituents exert different effects as a consequence of the orientation of the two phenyl rings, the $\beta$-phenyl ring being close to parallel to the olefinic double bond, while the phenyl moiety in the $\alpha$ position is turned to a tilted orientation, as revealed by the published structures computed by using ab initio methods $[88,124]$. 
Table 2

Effects of the substituent position on the enantioselective hydrogenations of monomethoxy- and monofluorosubstituted 2,3-diphenylpropenoic acids

\begin{tabular}{|c|c|c|c|c|c|c|c|c|}
\hline \multirow[t]{2}{*}{ Substrate } & \multicolumn{2}{|c|}{ Substituent on } & \multirow[t]{2}{*}{$\mathrm{r}_{\mathrm{u}}^{\mathrm{a}}$} & \multirow[t]{2}{*}{$\mathrm{r}_{\mathrm{m}}{ }^{\mathrm{a}}$} & \multirow[t]{2}{*}{$\mathrm{r}_{\mathrm{BA}}^{\mathrm{b}}$} & \multirow[t]{2}{*}{ ee $(\%)$} & \multirow[t]{2}{*}{$\mathrm{ee}_{\mathrm{BA}}^{\mathrm{b}}(\%)$} & \multirow{2}{*}{$\begin{array}{l}e^{e{ }_{B A}}{ }^{c} / X^{d} \\
(\%)\end{array}$} \\
\hline & $\alpha$-Phenyl & $\beta$-Phenyl & & & & & & \\
\hline 1 & $\mathrm{H}$ & $\mathrm{H}$ & 50.8 & 8.6 & 12.4 & 70 & 73 & $80 / 99$ \\
\hline 2 & $2-\mathrm{MeO}$ & $\mathrm{H}$ & 22.9 & 5.7 & 11.1 & 76 & 85 & $86 / 42$ \\
\hline 3 & $3-\mathrm{MeO}$ & $\mathrm{H}$ & 49.6 & 12.5 & 19.0 & 71 & 75 & $80 / 99$ \\
\hline 4 & 4-MeO & $\mathrm{H}$ & 45.1 & 10.8 & 21.0 & 70 & 77 & $80 / 96$ \\
\hline 13 & $4-\mathrm{MeO}$ & $\mathrm{H}$ & 51.2 & 7.3 & 5.8 & 35 & 38 & $40 />99$ \\
\hline 5 & $\mathrm{H}$ & $4-\mathrm{MeO}$ & 41.7 & 6.2 & 17.8 & 83 & 89 & $89 / 76$ \\
\hline 6 & $\mathrm{H}$ & $3-\mathrm{MeO}$ & 38.5 & 7.9 & 31.9 & 77 & 87 & $90 />99$ \\
\hline 7 & $\mathrm{H}$ & 2-MeO & 49.2 & 2.2 & 3.1 & 13 & 10 & $10 / 43$ \\
\hline 16 & $\mathrm{H}$ & $4-\mathrm{F}$ & 41.8 & 11.0 & 18.8 & 73 & 84 & $86 / 99$ \\
\hline 17 & $\mathrm{H}$ & $2-\mathrm{F}$ & 49.5 & 8.5 & 6.8 & 27 & 22 & $16 / 82$ \\
\hline 18 & $2-\mathrm{F}$ & $\mathrm{H}$ & 20.1 & 11.0 & 14.4 & 80 & 84 & $85 / 99$ \\
\hline
\end{tabular}

Reaction conditions: $25 \mathrm{mg} \mathrm{5 \%} \mathrm{Pd} / \mathrm{Al}_{2} \mathrm{O}_{3}{ }^{\mathrm{P}}, 5 \mathrm{~cm}^{3} \mathrm{DMF}+2.5$ vol. $\% \mathrm{H}_{2} \mathrm{O}, 0.025 \mathrm{mmol} \mathrm{CD}, 0.5 \mathrm{mmol}$ substrate, $0.1 \mathrm{MPa} \mathrm{H}_{2}, 294 \mathrm{~K}$, conversions $>98 \%$ in $2 \mathrm{~h}$ (unmodified) $-8 \mathrm{~h}$ (modified)

${ }^{\mathrm{a}} \mathrm{r}_{\mathrm{u}}$ and $\mathrm{r}_{\mathrm{m}}$ are the initial rates $\left(\mathrm{mmol} \mathrm{h}^{-1} \mathrm{~g}^{-1}\right)$ obtained in the absence and the presence of CD.

${ }^{\mathrm{b}} \mathrm{r}_{\mathrm{BA}}$ and $\mathrm{ee}_{\mathrm{BA}}$ are the initial rates $\left(\mathrm{mmol} \mathrm{h}^{-1} \mathrm{~g}^{-1}\right)$ and ee obtained in the presence of $\mathrm{CD}$ and $0.5 \mathrm{mmol} \mathrm{BA}$.

${ }^{\mathrm{c}}$ ee obtained at a reaction temperature of $275 \mathrm{~K}$ in the presence of BA as additive.

${ }^{\mathrm{d}}$ Conversions obtained in $8 \mathrm{~h}$ at $275 \mathrm{~K}$, using BA as additive.

Accordingly, the 2-methoxy group on the $\alpha$-phenyl ring hinders the adsorption of the acid and decreases its hydrogenation rate $\left(r_{u}\right)$. Moreover, this substituent hindered the adsorption of the prochiral acid on the pro- $R$ face to a larger extent as compared with the unsubstituted acid, probably because of the steric repulsion between the modifier and this group. On the other hand, the 2-methoxy group on the $\beta$-phenyl ring inhibited the stereoselective interaction between the modifier and the acid, though in the absence of CD this acid was easily hydrogenated. The electronic effect of this group is similar to that of the 4-methoxy substituent, as illustrated by the acidities of $\mathbf{1}, \mathbf{5}$ and $\mathbf{7}\left(\mathrm{pK}_{\mathrm{a}} 7.00,7.23\right.$ and 7.30, respectively [125]). Thus, both substituted compounds are slightly weaker acids than $\mathbf{1}$ and are transformed to more basic carboxylates, leading to increases in the strength of the modifier-substrate interaction. Hence, the drastic differences in behaviour of 5 and 7 cannot be interpreted on the basis of the electronic effects of the substituents. Thus, the low ee observed in the hydrogenation of 7 is due to the inhibited interaction of this acid with CD adsorbed on the metal surface, due to the steric hindrance of the 2-methoxy group. The above 
suggestions correlate well with the effects of BA on the initial rates and ee-s obtained in the hydrogenations of $\mathbf{2}$ and 7. Whereas significant increases in ee and the initial rate were obtained on the use of BA in the hydrogenation of $\mathbf{2}$, in that of $7 \mathrm{r}_{\mathrm{BA}}$ was still very low and ee decreased in the presence of BA. Thus, the latter acid barely interacts with CD during the hydrogenation.

The presence of the 3-methoxy substituent on the $\beta$-phenyl ring (6) led to a significant enantioselectivity increase as compared with $\mathbf{1}$. As the effect of the 4-methoxy substituent has been explained in previous studies in terms of an increase in the electron density of the extended conjugated $\pi$-system [70], the above observation is rather unexpected. The 3methoxy substituent on the $\beta$-phenyl ring increases the electron density in the ortho and para positions as demonstrated by the acidities of the substituted methoxycinnamic acids: $\mathrm{pK}_{\mathrm{a}} 3$ methoxycinnamic acid $<\mathrm{pK}_{\mathrm{a}}$ cinnamic acid $<\mathrm{pK}_{\mathrm{a}}$ 4-methoxycinnamic acid $[126,127]$. Further studies are needed to reveal the reason for the observed behaviour, which could be either the steric effect or the additional interaction of the 3-methoxy substituent with the modifier. The presence of BA increased the initial rates and ee significantly when the methoxy substituent was in the meta or para position on either the $\alpha$ - or the $\beta$-phenyl ring. It is interesting that the substituent in the ortho position on the $\beta$-phenyl ring hinders the selective interaction with the modifier, while that in the meta position on the same ring makes this interaction more stereospecific, leading to ee values close to that obtained with the 4-methoxy-substituted compound or even surpassing this at low reaction temperature. To the best of our knowledge, the high ee values obtained at low temperature in the hydrogenation of $5(89 \%)$ and $\mathbf{6}(90 \%)$ were unprecedented in the hydrogenation of monosubstituted $(E)$-2,3-diphenylpropenoic acids.

The orientation of the $\beta$-phenyl ring is crucial for high enantioselectivity. The hydrogenation of $\mathbf{1 3}$ resulted in an ee about half of that for $\mathbf{4}$, in line with the results obtained in the hydrogenations of the two (E)-2,3-diphenylpropenoic acid isomers [55]. Considering the large acidity difference between these isomers [128], the much lower basic character of the carboxylate formed from the $Z$ isomer may be the cause of the poor ee. The decrease in the initial reaction rate in the hydrogenation of $\mathbf{1 3}$ following the addition of BA also indicated a loose contact between $\mathrm{CD}$ and this acid. Furthermore, the geometry of the $Z$ isomer may not be appropriate for establishment of an efficient interaction with the modifier.

The above results revealed the crucial importance of both the acidity of the substrate, 
influenced by the substituents (by electronic effects), and the geometry of the acid, affected by the hindrances of the substituents (steric effects), in the formation of an efficient contact between the modifier and the substrate in order to obtain high enantioselectivity.

The hydrogenations of $(E)$-2,3-diphenylpropenoic acids substituted with fluorine in the ortho position on the $\alpha$-phenyl ring, or in the ortho or para position on the $\beta$-phenyl ring are compared with those of the unsubstituted and methoxy-substituted acids in Table 2. The initial rate over the unmodified catalyst decreased only slightly and to a similar extent as the effect of either a methoxy or a fluoro substituent in a given position on the $\beta$-phenyl ring. The decrease is a consequence of the reduced adsorption strengths and accordingly the lower surface concentrations of the reaction intermediates formed from the substituted acids as compared with 1. Larger decreases in $r_{u}$ were observed in the hydrogenations of the compounds substituted in the ortho position on the $\alpha$-phenyl ring, due to the orientation of this ring $[88,124,129]$. The tilted arrangement of this phenyl group with respect to the acrylic acid moiety results in stronger hindering of the adsorption on the $\mathrm{C}=\mathrm{C}$ group by both the ortho-methoxy and the ortho-fluoro substituent. The initial rates in the presence of $\mathrm{CD}\left(\mathrm{r}_{\mathrm{m}}\right)$ decreased in all these reactions as compared with the racemic hydrogenations $\left(r_{u}\right)$.

Higher ee-s were obtained in the reactions of the acids substituted in the para position on the $\beta$-phenyl ring (5 and 16) or in the ortho position on the $\alpha$-phenyl ring ( 2 and 18). On the other hand, the $r_{m}$ values decreased in the hydrogenations of the methoxy-substituted compounds 5 and $\mathbf{2}$, while a surprising increase in $r_{m}$ was observed as the effect of fluoro in the same positions as compared with 1. Substitution in the ortho position on the $\beta$-phenyl ring (7 and 17) decreased both $r_{m}$ and ee, with the fluoro substituent affecting both values less than the methoxy group.

The higher ee obtained in the hydrogenation of $\mathbf{5}$ as compared with $\mathbf{1}$ was attributed to the electron-releasing resonance effect of the methoxy substituents in the para position [70]. However, the fluoro substituent in this position has an opposite, electron-withdrawing effect, as indicated by the signs of the Hammett parameters $\left(\sigma\right.$ para $-\mathrm{CH}_{3} \mathrm{O}=-0.27$ or -0.17 ; $\sigma$ para $-\mathrm{F}$ $=+0.06$ or +0.15$)[130-133]$ and also by the acidities of cinnamic acid and its fluoro derivative (cinnamic acid $\mathrm{pK}_{\mathrm{a}}=4.44$; para-fluorocinnamic acid $\mathrm{pK}_{\mathrm{a}}=4.21$ ) [134], and therefore does not increase the interaction strength with CD. Furthermore, over the unmodified catalyst the two substituents had similar effects on the initial rate, while in the presence of CD they displayed opposite effects on $\mathrm{r}_{\mathrm{m}}$. 
The ee value obtained over a heterogeneous catalyst is influenced by the fraction of the chiral surface sites, the intrinsic enantiodifferentiating ability of a surface chiral site and the ratio of the turnover frequencies on modified and unmodified sites (if the fraction modified sites/total active sites $<1$ ). In the studied reactions, the fraction of the chiral sites was not influenced significantly by the substitution of the acids. The enantiodifferentiating ability of a chiral site was improved by the methoxy substituent due to the increase in strength of the substrate-modifier interaction [70], but not by the para-fluoro substituent. On the other hand, the rate-determining step over the modified catalyst was shown to be the desorption of the product [66]. In this step, the olefinic bond is already hydrogenated [135]. Lacking an extended conjugated system, the product interacts with the surface only via the $\beta$-phenyl moiety, while it is bonded to CD via the carboxylic group. Accordingly, instead of enhancing the interaction with the modifier the para-fluoro substituent on the $\beta$-phenyl ring, decreased the adsorption strength on the Pd surface, leading to an increase in the turnover frequency on the modified sites and consequently to an increase in ee. The use of BA as additive resulted in increases in ee and the initial rate in the hydrogenations of both $\mathbf{5}$ and $\mathbf{1 6}$.

The drastic decreases in ee and $r_{m}$ observed in the hydrogenation of ortho-methoxysubstituted 7 was explained by the steric effect of the substituent. This was confirmed by the results obtained with $\mathbf{1 7}$. The steric hindrance of the ortho-fluoro substituent on the $\beta$-phenyl ring is much smaller than that of the methoxy group, and it is therefore reasonable to obtain a higher ee in the hydrogenation of $\mathbf{1 7}$ than in that of $\mathbf{7}$.

The higher ee obtained in the hydrogenation of the fluoro-substituted $\mathbf{1 8}$ as compared with 2 was surprising, as we presumed that the ee increase observed in the hydrogenation of 2 was mostly due to steric effects of the substituent. Moreover, the $r_{m}$ value obtained in the hydrogenation of $\mathbf{1 8}$ was higher as compared with $\mathbf{1}$. The electronic effect of the substituents may be disregarded as a plausible cause, as fluoro has an opposite electronic effect to that of the methoxy group and the electronic effects of the substituents can hardly be felt, due to the tilt of the $\alpha$-phenyl ring [88,124,129]. As fluoro significantly increased both ee (higher than in the hydrogenations of $\mathbf{1 6}$ and 2) and $r_{m}$, this substituent both enhanced the strength of the modifier-acid interaction and decreased the strength of adsorption on the surface. The former may be explained by the formation of an additional interaction of the substituents in the ortho position on the $\alpha$-phenyl ring with the absorbed $\mathrm{CD}$ via formation of a H-bond. Although covalently bonded F is a weak H-bond acceptor [136-138], it has been shown that is able to 
form H-bonds during hydrogenations, leading to the stabilization of compounds and playing a crucial role in the outcome of a reaction [139]. In the hydrogenation of the unsaturated acids, $\mathrm{CD}$ is protonated by the substrate and an additional interaction of the substituent in the ortho position on the $\alpha$-phenyl ring, either with the $\mathrm{H}-\mathrm{N}^{+}(\mathrm{CD})$ or with a $\mathrm{H}-\mathrm{C}(\mathrm{CD})$, may explain the effects of these substituents. Another possible explanation could be the influence of these substituents on the dipole moment (the orientation of the vector of the dipole moment) of the acid molecule, leading to a favourable effect on the modifier-acid interaction, as was suggested in connection with the hydrogenation of trifluoromethyl ketones over Pt [138]. These assumptions may explain the effect of this substituent on ee, but further studies are clearly needed to reveal the exact mode of interaction of CD with ortho-substituted $\alpha$-phenyl compounds.

At low temperature, increases in ee were observed in the hydrogenations of both methoxy- and fluoro-substituted compounds, with the except ions of 7 and 17. The initial rates decreased, but the tendencies observed at room temperature persisted. Under these reaction conditions, the ee-s obtained in the hydrogenations of the ortho-substituted compounds $\mathbf{2}$ and $\mathbf{1 8}$ were almost identical, whereas a significant difference in ee was observed in the hydrogenations of $\mathbf{5}$ and 16, in favour of the methoxy-substituted acid. These observations appear to confirm the above suggestions concerning the role of these substituents.

\subsubsection{Hydrogenations of dimethoxy derivatives}

The report of Nitta et al. on the hydrogenations of 4-methoxy derivatives [70,71] indicates that higher ee-s may be obtained in the hydrogenations of dimethoxy derivatives substituted on both phenyl rings. Moreover, confirmation of the effect of the position of the methoxy substituent was sought from the hydrogenations of the disubstituted acids. The results relating to the hydrogenations of selected dimethoxy derivatives are presented in Table 3. 
Table 3

Effect of the positions of the substituents on the hydrogenations of dimethoxy-substituted (E)-2,3diphenylpropenoic acid derivatives

\begin{tabular}{|c|c|c|c|c|c|c|c|c|}
\hline \multirow[t]{2}{*}{ Substrate } & \multicolumn{2}{|c|}{ Substituent on } & \multirow[t]{2}{*}{$\mathrm{r}_{\mathrm{u}}^{\mathrm{a}}$} & \multirow[t]{2}{*}{$\mathrm{r}_{\mathrm{m}}^{\mathrm{a}}$} & \multirow[t]{2}{*}{$\mathrm{r}_{\mathrm{BA}}^{\mathrm{b}}$} & \multirow[t]{2}{*}{ ee $(\%)$} & \multirow[t]{2}{*}{$\mathrm{ee}_{\mathrm{BA}}^{\mathrm{b}}(\%)$} & \multirow{2}{*}{$\begin{array}{l}\mathrm{ee}_{\mathrm{BA}}{ }^{\mathrm{c}} / \mathrm{X}^{\mathrm{d}} \\
(\%)\end{array}$} \\
\hline & $\alpha$-Phenyl & $\beta$-Phenyl & & & & & & \\
\hline 8 & 2-MeO & 4-MeO & 8.2 & 3.7 & 3.8 & 83 & 90 & $92 / 60$ \\
\hline 9 & 3-MeO & 3-MeO & 21.4 & 7.1 & 14.4 & 75 & 85 & $87 / 92$ \\
\hline 10 & 4-MeO & 2-MeO & 27.8 & 9.0 & 5.3 & 10 & 10 & $8 / 51$ \\
\hline 11 & 4-MeO & 3-MeO & 18.2 & 6.3 & 9.9 & 78 & 86 & $88 / 96$ \\
\hline 12 & 4-MeO & 4-MeO & 28.9 & 4.0 & 7.5 & 86 & 89 & $90 / 73$ \\
\hline 14 & 4-MeO & 3-MeO & 38.6 & 5.1 & 3.2 & 34 & 30 & - \\
\hline 15 & 4-MeO & 4-MeO & 54.5 & 3.8 & 3.5 & 2 & 9 & - \\
\hline
\end{tabular}

Reaction conditions: $25 \mathrm{mg} 5 \% \mathrm{Pd} / \mathrm{Al}_{2} \mathrm{O}_{3}{ }^{\mathrm{P}}, 5 \mathrm{~cm}^{3} \mathrm{DMF}+2.5$ vol. $\% \mathrm{H}_{2} \mathrm{O}, 0.025 \mathrm{mmol} \mathrm{CD}, 0.5 \mathrm{mmol}$ substrate, $0.1 \mathrm{MPa} \mathrm{H}_{2}, 294 \mathrm{~K}$, conversions $>98 \%$ in $2 \mathrm{~h}$ (unmodified) $-8 \mathrm{~h}$ (modified)

${ }^{\mathrm{a}} \mathrm{r}_{\mathrm{u}}$ and $\mathrm{r}_{\mathrm{m}}$ are the initial rates $\left(\mathrm{mmol} \mathrm{h}^{-1} \mathrm{~g}^{-1}\right)$ obtained in the absence and the presence of CD.

${ }^{\mathrm{b}} \mathrm{r}_{\mathrm{BA}}$ and $\mathrm{ee}_{\mathrm{BA}}$ are the initial rates $\left(\mathrm{mmol} \mathrm{h}^{-1} \mathrm{~g}^{-1}\right)$ and ee obtained in the presence of $\mathrm{CD}$ and $0.5 \mathrm{mmol} \mathrm{BA}$.

${ }^{\mathrm{c}}$ ee obtained at a reaction temperature of $275 \mathrm{~K}$ in the presence of BA as additive.

${ }^{\mathrm{d}}$ Conversions obtained in $8 \mathrm{~h}$ at $275 \mathrm{~K}$, using BA as additive.

In the hydrogenations of these compounds, the effects of the methoxy substituents on both the initial rates and the ee-s were similar to those in the reactions of the monosubstituted acids. As a result of the combined effect of the 2-methoxy substituent on the $\alpha$-phenyl ring and the 4-methoxy group on the $\beta$-phenyl ring, the ee obtained in the presence of BA in the hydrogenation of $\mathbf{8}$ exceeded even the value observed for the di-4-methoxy-substituted compound 12. On the other hand, in spite of the presence of the 4-methoxy group on the $\alpha$ phenyl ring (10), the 2-methoxy substituent on the $\beta$-phenyl ring decreased ee as in the hydrogenation of 7. Furthermore, in the reaction of 10, the initial rate decreased in the presence of BA, supporting the conclusions previously drawn from the behaviour of 7. High enantioselectivities were obtained in the hydrogenations of the compounds bearing 3-methoxy substituents on the $\beta$ or both phenyl rings (11 and 9, respectively). The optical purities obtained in the hydrogenations of $\mathbf{1 4}$ were similar to those with $\mathbf{1 3}$, while nearly racemic products resulted from the reaction of $\mathbf{1 5}$.

These experiments showed that a para-methoxy substituent on either of the phenyl rings of (E)-2,3-diphenylpropenoic acid results in increased enantioselectivity as compared with the unsubstituted acid. 


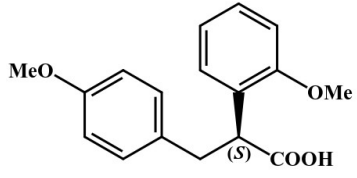

ee $92 \%$

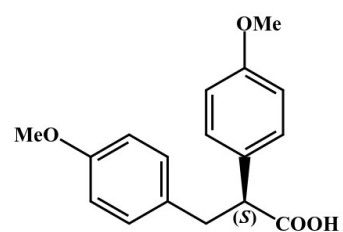

ee $90 \%$

\section{Scheme 18}

The two dimethoxy-substituted derivatives obtained with the best optical purities

Moreover, substitution in the meta position on both rings and an ortho substituent on the $\alpha$ phenyl ring also lead to increased optical purity of the saturated product; the latter was found to be even more efficient than para-substitution on the same phenyl ring. As a consequence, high ee-s could be obtained in the hydrogenations of several methoxy-substituted compounds.

Besides being of practical importance, due to the easy preparation of chiral carboxylic acids of high optical purity such as (S)-2-(2-methoxyphenyl)-3-(4-methoxyphenyl)propionic acid and (S)-2-(4-methoxyphenyl)-3-(4-methoxyphenyl)-propionic acid (see Scheme 18), the results obtained in this study may also serve as a useful starting point for elucidation of the structure of the intermediate complex of the reaction.

\subsubsection{Hydrogenations of mixed methoxy-and fluoro-disubstituted derivatives}

The hydrogenations of $(E)$-2,3-diphenylpropenoic acids substituted on both phenyl rings with two methoxy groups resulted in lower $r_{u}$ and $r_{m}$ values, but higher ee-s than for the monosubstituted derivatives, except when the $\beta$-phenyl ring was substituted in the ortho position [70]. We examined the effect of replacement of one of the methoxy substituents with a fluoro atom. The results obtained at room temperature are to be seen in Table 4, compared with dimethoxy-substituted compounds $\mathbf{8}$ and $\mathbf{1 2}$.

In the hydrogenations of the compounds substituted in both para positions, replacement of the electron-releasing methoxy substituent on the $\beta$-phenyl ring with a fluoro atom (19) decreased ee as compared with the dimethoxy-substituted acid 12, while in the hydrogenation of 20, with a para-fluoro substituent on the $\alpha$-phenyl ring, similar ee-s were obtained as for 12. 


\section{Table 4.}

Effects of the positions of methoxy or fluoro substituents on the hydrogenations of disubstituted (E)-2,3diphenylpropenoic acid derivatives

\begin{tabular}{|c|c|c|c|c|c|c|c|c|c|}
\hline \multirow[t]{2}{*}{ Substrate } & \multicolumn{2}{|c|}{ Substituent on } & \multirow[t]{2}{*}{$\mathrm{r}_{\mathrm{u}}^{\mathrm{a}}$} & \multirow[t]{2}{*}{$\mathrm{r}_{\mathrm{m}}^{\mathrm{a}}$} & \multirow[t]{2}{*}{$\mathrm{r}_{\mathrm{BA}}{ }^{\mathrm{b}}$} & \multirow[t]{2}{*}{ ee $(\%)$} & \multirow[t]{2}{*}{$\mathrm{ee}_{\mathrm{BA}}^{\mathrm{b}}(\%)$} & \multirow{2}{*}{$\begin{array}{l}\mathrm{ee}_{\mathrm{BA}} \mathrm{c} / \mathrm{X}^{\mathrm{d}} \\
(\%)\end{array}$} & \multirow[t]{2}{*}{$\mathrm{r}_{\mathrm{BA}}{ }^{\mathrm{c}}$} \\
\hline & $\alpha$-Phenyl & $\beta$-Phenyl & & & & & & & \\
\hline 12 & 4-MeO & 4-MeO & 28.9 & 4.0 & 7.5 & 86 & 89 & $90 / 73$ & 2.4 \\
\hline 19 & 4-MeO & $4-F$ & 15.9 & 4.1 & 10.4 & 74 & 82 & $84 / 82^{\mathrm{e}}$ & 3.9 \\
\hline 20 & $4-\mathrm{F}$ & 4-MeO & 28.4 & 8.2 & 11.7 & 83 & 88 & $90 / 88^{\mathrm{e}}$ & 3.8 \\
\hline 21 & $4-\mathrm{F}$ & 2-MeO & 70.8 & 3.4 & 3.3 & 24 & 20 & - & - \\
\hline 8 & 2-MeO & 4-MeO & 8.2 & 3.7 & 3.8 & 83 & 90 & $92 / 60 / 99^{f}$ & 1.9 \\
\hline 22 & $2-\mathrm{F}$ & 4-MeO & 10.5 & 4.5 & 8.5 & 85 & 92 & $93 / 87^{\mathrm{e}} / 99^{\mathrm{f}}$ & 3.4 \\
\hline 23 & 2-MeO & $4-\mathrm{F}$ & 7.1 & 2.9 & 5.4 & 86 & 93 & $96 / 95^{\mathrm{e}} / 99$ & 2.4 \\
\hline 24 & 2-MeO & $3-\mathrm{F}$ & 14.9 & 4.1 & 6.8 & 87 & 91 & 93/93e/99 & 3.3 \\
\hline 25 & 2-MeO & $2-\mathrm{F}$ & 17.6 & 2.1 & 5.5 & 20 & 29 & - & - \\
\hline
\end{tabular}

Reaction conditions: $25 \mathrm{mg} \mathrm{5 \%} \mathrm{Pd} / \mathrm{Al}_{2} \mathrm{O}_{3}{ }^{\mathrm{P}}, 5 \mathrm{~cm}^{3} \mathrm{DMF}+2.5$ vol. $\% \mathrm{H}_{2} \mathrm{O}, 0.025 \mathrm{mmol} \mathrm{CD}, 0.5 \mathrm{mmol}$ substrate, $0.1 \mathrm{MPa} \mathrm{H}_{2}, 294 \mathrm{~K}$, conversions of $98-100 \%$ in 2 (unmodified) - $8 \mathrm{~h}$ (modified)

${ }^{\mathrm{a}} \mathrm{r}_{\mathrm{u}}$ and $\mathrm{r}_{\mathrm{m}}$ are the initial rates $\left(\mathrm{mmol} \mathrm{h}^{-1} \mathrm{~g}^{-1}\right)$ obtained in the absence and the presence of CD.

${ }^{\mathrm{b}} \mathrm{r}_{\mathrm{BA}}$ and $\mathrm{ee}_{\mathrm{BA}}$ are the initial rates $\left(\mathrm{mmol} \mathrm{h}^{-1} \mathrm{~g}^{-1}\right)$ and ee-s obtained in the presence of $\mathrm{CD}$ and $0.5 \mathrm{mmol} \mathrm{BA}$.

${ }^{\mathrm{c}} \mathrm{r}_{\mathrm{BA}}$ and ee obtained at a reaction temperature of $275 \mathrm{~K}$ in the presence of BA as additive.

${ }^{\mathrm{d}}$ Conversions obtained in $8 \mathrm{~h}$ at $275 \mathrm{~K}$, using BA as additive.

${ }^{\mathrm{e}}$ Conversions obtained in $6 \mathrm{~h}$ at $275 \mathrm{~K}$, using BA as additive.

${ }^{\mathrm{f}}$ Conversions obtained in $24 \mathrm{~h} \mathrm{(8)}$ and $10 \mathrm{~h} \mathrm{(22)}$ at $275 \mathrm{~K}$, using BA as additive.

Accordingly, strong electron-releasing groups are necessary in the para position on the $\beta$ phenyl ring in order to obtain high ee, while the effect of the para substituent on the $\alpha$-phenyl ring is smaller. This confirmed the proposed electronic effect of the substituent on the $\beta$ phenyl ring, due to its influence on the electron distribution along the conjugated system, while the substituents on the $\alpha$-phenyl ring have barely any effect. The shift of the methoxy substituent on the $\beta$-phenyl ring to the ortho position (21) decreased ee and $r_{m}$, similarly as for the hydrogenations of all the compounds substituted with either a methoxy group or a fluoro atom in this position, such as 7, 17 and $\mathbf{2 5}$, irrespective of the absence or presence of other substituents on the $\alpha$-phenyl ring.

The best ee in our study of dimethoxy derivatives was obtained in the hydrogenation of 8, bearing a methoxy substituent in the ortho position on the $\alpha$-phenyl ring. Replacement of the methoxy group in this position with a fluoro substituent (22) further increased ee, in accordance with the hydrogenations of the monosubstituted derivatives $\mathbf{2}$ and $\mathbf{1 8}$. Thus, an ee of $92 \%$ ee was obtained even at room temperature in the presence of BA. These results 
confirmed the beneficial effect of the fluoro substituent in the ortho position on the $\alpha$-phenyl. As discussed previously, the results may be explained by a combination of the fluoro substituent decreasing the adsorption strength and the interaction of this substituent with the absorbed CD.

Even higher ee was obtained when the para-methoxy group on the $\beta$-phenyl ring in $\mathbf{8}$ was replaced with fluorine (23). Thus, the effect of fluoro in the para position was sufficient to reach a high ee when an ortho substituent on the $\alpha$-phenyl ring enhanced the interaction of the acid with the modifier. Moreover, similar results were obtained in the hydrogenation of 24 with fluoro in the meta position on the $\beta$-phenyl ring. The surprisingly beneficial effects of both methoxy and fluoro in this position is in contrast with the electronic effects of these substituents. Both meta substituents have positive Hammett parameters $\left(\sigma\right.$ meta- $\mathrm{CH}_{3} \mathrm{O}=$ $+0.15 ; \sigma$ meta $-\mathrm{F}=+0.35$ [130-133]) and lead to increased acidities, as indicated by the $\mathrm{pK}_{\mathrm{a}}$ values of cinnamic acid and its meta-substituted derivatives (cinnamic acid $\mathrm{pK}_{\mathrm{a}}=5.68$; metamethoxycinnamic acid $\left.\mathrm{pK}_{\mathrm{a}}=5.44\right)$ [127]. Thus, the electronic effects of the substituents in the meta position would not increase the strength of interaction with the modifier. Although further studies are necessary to find an explanation for the increased ee obtained in the reaction of 24, the higher initial rate obtained in this hydrogenation as compared with $\mathbf{2 3}$ may indicate that the substituents in the meta position to some extent hinder the adsorption of these acids. This could lead to a higher rate over modified sites, increasing ee. We stress that both the meta and para substituents on the $\beta$-phenyl ring led to excellent ee only when their effect was complemented with the effect of the ortho substituent on the $\alpha$-phenyl ring. As mentioned earlier, it is also possible that these substituents affected the dipole moments of the unsaturated acids, both the meta and para substituents therefore leading to increases in the efficiency of the CD-acid interaction.

According to these results, high enantioselectivities can be obtained in the hydrogenation of disubstituted compounds bearing methoxy and fluoro substituents in appropriate positions. The ee values increased by a few per cent when the reaction temperature was decreased (see Table 4). Although the initial rates were low under these reaction conditions full conversions could be obtained by extending the hydrogenation time without altering the stereochemical outcome of the reactions. 

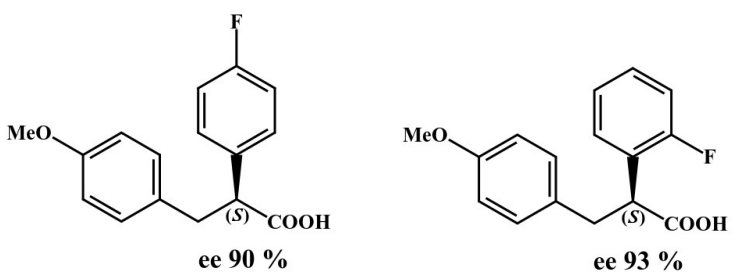

ee $93 \%$

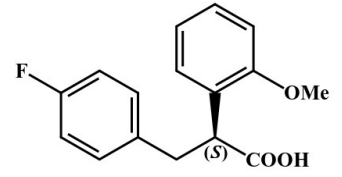

ee $96 \%$

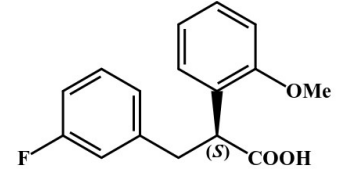

ee $93 \%$

\section{Scheme 19}

The methoxy and fluoro disubstituted derivatives obtained in the best ee

Under these conditions, the saturated products could be prepared in excellent (up to 93-96\%) optical purities (22, 23 and 24) (see Scheme 19), which is unprecedented in the enantioselective hydrogenations of prochiral carboxylic acids over a modified heterogeneous catalyst.

\subsubsection{Hydrogenations of difluoro derivatives}

Comparison of the results obtained in the hydrogenations of the derivatives disubstituted with both fluoro and methoxy groups with those obtained in the reactions of the corresponding dimethoxy derivatives indicated that the fluoro substituent in certain compounds is even more efficient than the methoxy group in increasing ee. This observation led us to investigate the hydrogenations of some difluoro-substituted derivatives (Table 5).

The enantioselective hydrogenation of the di-para-fluoro-substituted compound $\mathbf{2 6}$ resulted in an ee close to that obtained in the reaction of $\mathbf{1 9}$, but lower than those in the reactions of 12 and 20. This confirmed our previous observation that the para-fluoro substituent on the $\beta$-phenyl ring is less efficient in enhancing the modifier-acid interaction than the methoxy group. Similar, but slightly higher ee-s were obtained in the hydrogenation of 27 , with the substituent in the meta position, accompanied by much higher $r_{m}$ and $r_{a}$ as compared with 26, similarly as in the hydrogenation of $\mathbf{2 4}$ in comparison with that of 23.

This demonstrated that the effect of the meta substituent on the $\beta$-phenyl ring is general and independent of the position of the substituent on the $\alpha$-phenyl ring. In light of the findings described in the previous subsections, the low ee obtained in the reaction of $\mathbf{2 8}$ as an effect of the ortho fluoro substituent on the $\beta$-phenyl ring could be anticipated. 
Table 5

Effects of the positions of the fluoro substituent on the hydrogenations of disubstituted (E)-2,3diphenylpropenoic acid derivatives

\begin{tabular}{|c|c|c|c|c|c|c|c|c|c|}
\hline \multirow[t]{2}{*}{ Substrate } & \multicolumn{2}{|c|}{ Substituent on } & \multirow[t]{2}{*}{$\mathrm{r}_{\mathrm{u}}^{\mathrm{a}}$} & \multirow[t]{2}{*}{$\mathrm{r}_{\mathrm{m}}{ }^{\mathrm{a}}$} & \multirow[t]{2}{*}{$\mathrm{r}_{\mathrm{BA}}{ }^{\mathrm{b}}$} & \multirow[t]{2}{*}{ ee $(\%)$} & \multirow[t]{2}{*}{$e{ }_{B A}^{b}(\%)$} & \multirow{2}{*}{$\begin{array}{l}e_{\mathrm{BA}_{\mathrm{A}}}^{\mathrm{c}} / \mathrm{X}^{\mathrm{d}} \\
(\%)\end{array}$} & \multirow[t]{2}{*}{$\mathrm{r}_{\mathrm{BA}}{ }^{\mathrm{c}}$} \\
\hline & $\alpha$-Phenyl & $\beta$-Phenyl & & & & & & & \\
\hline 26 & $4-F$ & $4-\mathrm{F}$ & 14.4 & 4.8 & 8.5 & 73 & 84 & $85 / 66^{\mathrm{e}} / 99^{\mathrm{f}}$ & 3.0 \\
\hline 27 & $4-\mathrm{F}$ & $3-\mathrm{F}$ & 24.1 & 14.0 & 26.7 & 78 & 85 & $89 / 96^{\mathrm{e}} / 99$ & 4.2 \\
\hline 28 & $4-\mathrm{F}$ & $2-\mathrm{F}$ & 33.5 & 6.9 & 5.9 & 27 & 25 & - & - \\
\hline 29 & $2-\mathrm{F}$ & $4-\mathrm{F}$ & 8.9 & 4.8 & 10.5 & 86 & 91 & $96 / 93^{\mathrm{e}} / 99$ & 3.2 \\
\hline 30 & $2-\mathrm{F}$ & $3-\mathrm{F}$ & 16.5 & 10.2 & 11.9 & 84 & 87 & $90 / 94^{\mathrm{e}} / 99$ & 3.8 \\
\hline
\end{tabular}

Reaction conditions: $25 \mathrm{mg} \mathrm{5 \%} \mathrm{Pd} / \mathrm{Al}_{2} \mathrm{O}_{3}{ }^{\mathrm{P}}, 5 \mathrm{~cm}^{3} \mathrm{DMF}+2.5$ vol. $\% \mathrm{H}_{2} \mathrm{O}, 0.025 \mathrm{mmol} \mathrm{CD}, 0.5 \mathrm{mmol}$ substrate, $0.1 \mathrm{MPa} \mathrm{H}_{2}, 294 \mathrm{~K}$, conversions of $98-100 \%$ in 2 (unmodified) - $8 \mathrm{~h}$ (modified)

${ }^{\mathrm{a}} \mathrm{r}_{\mathrm{u}}$ and $\mathrm{r}_{\mathrm{m}}$ are the initial rates $\left(\mathrm{mmol} \mathrm{h}^{-1} \mathrm{~g}^{-1}\right)$ obtained in the absence and the presence of CD.

${ }^{\mathrm{b}} \mathrm{r}_{\mathrm{BA}}$ and $\mathrm{ee}_{\mathrm{BA}}$ are the initial rates $\left(\mathrm{mmol} \mathrm{h}^{-1} \mathrm{~g}^{-1}\right)$ and ee obtained in the presence of $\mathrm{CD}$ and $0.5 \mathrm{mmol} \mathrm{BA}$.

${ }^{\mathrm{c}} \mathrm{r}_{\mathrm{BA}}$ and ee obtained at a reaction temperature of $275 \mathrm{~K}$ in the presence of BA as additive.

${ }^{\mathrm{d}}$ Conversions obtained in $8 \mathrm{~h}$ at $275 \mathrm{~K}$, using BA as additive.

${ }^{\mathrm{e}}$ Conversions obtained in $6 \mathrm{~h}$ at $275 \mathrm{~K}$, using BA as additive.

${ }^{\mathrm{f}}$ Conversions obtained in more than $8 \mathrm{~h}$ at $275 \mathrm{~K}$, using BA as additive.

Higher ee values were obtained when the position of the fluoro on the $\alpha$-phenyl ring was changed to ortho (29 and 30) (see Scheme 20). Similar results were obtained as in the hydrogenations of $\mathbf{2 3}$ and $\mathbf{2 4}$, although the para-fluoro substituent was also efficient in the hydrogenation of the difluoro-substituted compounds in the absence of BA. The favourable effect of the fluoro substituent was evidenced even more by the results obtained at lower temperature (see Table 5). Thus, in the hydrogenation of 29 a similarly high ee (96\%) was obtained under these reaction conditions as in that of $\mathbf{2 3}$, the highest value reached to date in this reaction. The initial rates usually exceeded those obtained in the hydrogenations of the methoxy-substituted derivatives, even at decreased temperature, in accordance with the weaker adsorption of the fluoro-substituted compounds.<smiles>O=C(O)[C@H](Cc1ccc(F)cc1)c1ccccc1F</smiles>

ee $96 \%$

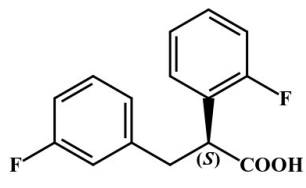

ee $90 \%$

Scheme 20

The difluoro substituted acids obtained with the best ee-s 
The hydrogenations of the difluoro derivatives indicated even more clearly the higher efficiency of the ortho substituents on the $\alpha$-phenyl ring in increasing ee in comparison with the substituents in the para position on the same ring.

According to these results, similarly high or even higher ee-s may be obtained in the hydrogenations of fluoro-substituted $(E)$-2,3-diphenylpropenoic acids as in the reactions of the methoxy-substituted derivatives. This is surprising considering the low steric hindrance and the electron-withdrawing effect of fluoro, but ee was increased by the additional interactions of this substituent in some position with either the modifier or the surface.

\subsubsection{Hydrogenations of methyl-substituted derivatives}

The methyl group has an electron-releasing inductive effect, practically no H-bonding ability and a steric effect intermediate between those of the methoxy and fluoro groups. Having a negative Hammett parameter $\left(\sigma\right.$ para $\left.-\mathrm{CH}_{3}=-0.13\right)$ [130-132] and slightly increasing the acidity $\left(1 \mathrm{pK}_{\mathrm{a}}=7.00 ; \mathbf{3 1} \mathrm{pK}_{\mathrm{a}}=6.99\right)$ [125], the methyl group in the para position on the $\beta$ phenyl ring (31) increased ee as compared with $\mathbf{1}$ both in the absence and in the presence of BA, although this increase was much smaller than that in the reaction of $\mathbf{5}$ (Table 6). The initial rates obtained in the reactions of $\mathbf{3 1}$ are extremely informative The identical $r_{u}$ as for $\mathbf{5}$ and $\mathbf{1 6}$ and the higher $r_{m}$ as compared even with the fluoro-substituted acid supported our previous suggestions. Thus, it became clear-cut that the electronic effect of the para substituent on the $\beta$-phenyl ring is of paramount importance as concerns increasing the efficiency of the interaction with CD and obtaining a good ee. Furthermore, the steric effect of the substituent caused the weaker adsorption of $\mathbf{3 1}$ on modified sites, leading to an increased $r_{m}$ and contributing to the increase in ee.

The methyl group in the ortho position on the $\alpha$ phenyl ring (32) did not lead to significant ee and initial rate increases as compared with $\mathbf{1}$. This confirmed that neither the electronic nor the steric effects of the substituents in this position were decisive, but the formation of an additional interaction between the ortho substituents with lone electron pairs and the modifier is responsible for an ee increase in the hydrogenations of the compounds substituted in this position. A similar conclusion may be drawn from the ee-s observed in the hydrogenation of $\mathbf{3 3}$ and $\mathbf{3 4}$, the former giving an only slightly higher ee than that for $\mathbf{3 1}$ and the latter exhibiting similar behaviour as in $\mathbf{1 6}$. 
Table 6

Effects of the positions of the methyl substituent on the hydrogenations of mono- and disubstituted (E)-2,3diphenylpropenoic acid derivatives

\begin{tabular}{|c|c|c|c|c|c|c|c|c|c|}
\hline \multirow[t]{2}{*}{ Substrate } & \multicolumn{2}{|c|}{ Substituent on } & \multirow[t]{2}{*}{$\mathrm{r}_{\mathrm{u}}^{\mathrm{a}}$} & \multirow[t]{2}{*}{$\mathrm{r}_{\mathrm{m}}{ }^{\mathrm{a}}$} & \multirow[t]{2}{*}{$\mathrm{r}_{\mathrm{BA}}{ }^{\mathrm{b}}$} & \multirow[t]{2}{*}{ ee $(\%)$} & \multirow[t]{2}{*}{$\mathrm{ee}_{\mathrm{BA}}^{\mathrm{b}}(\%)$} & \multirow{2}{*}{$\begin{array}{l}\mathrm{ee}_{\mathrm{BA}} \mathrm{c} / \mathrm{X}^{\mathrm{d}} \\
(\%)\end{array}$} & \multirow[t]{2}{*}{$\mathrm{r}_{\mathrm{BA}}{ }^{\mathrm{c}}$} \\
\hline & $\alpha$-Phenyl & $\beta$-Phenyl & & & & & & & \\
\hline 31 & $\mathrm{H}$ & 4-Me & 41.9 & 15.9 & 20.4 & 74 & 76 & $80 / 74$ & 3.3 \\
\hline 32 & $2-\mathrm{Me}$ & $\mathrm{H}$ & 16.8 & 7.4 & 13.6 & 71 & 75 & $81 / 83$ & 2.5 \\
\hline 33 & $2-\mathrm{Me}$ & 4-Me & 6.6 & 3.0 & 2.5 & 76 & 77 & $83 / 40$ & 0.8 \\
\hline 34 & 2-Me & $4-\mathrm{F}$ & 5.8 & 2.8 & 5.2 & 75 & 84 & $84 / 85$ & 1.7 \\
\hline 35 & $2-\mathrm{F}$ & 4-Me & 13.3 & 8.1 & 6.9 & 81 & 84 & $85 / 87$ & 1.8 \\
\hline 36 & 2-MeO & 4-Me & 11.1 & 4.8 & 2.8 & 77 & 89 & $89 / 62$ & 1.1 \\
\hline
\end{tabular}

Reaction conditions: $25 \mathrm{mg} \mathrm{5 \%} \mathrm{Pd} / \mathrm{Al}_{2} \mathrm{O}_{3}{ }^{\mathrm{P}}, 5 \mathrm{~cm}^{3} \mathrm{DMF}+2.5$ vol. $\% \mathrm{H}_{2} \mathrm{O}, 0.025 \mathrm{mmol} \mathrm{CD}, 0.5 \mathrm{mmol}$ substrate, $0.1 \mathrm{MPa} \mathrm{H}_{2}, 294 \mathrm{~K}$, conversions $>95 \%$ in 2 (unmodified) - $8 \mathrm{~h}$ (modified)

${ }^{a} r_{u}$ and $r_{m}$ are the initial rates $\left(\mathrm{mmol} \mathrm{h}^{-1} \mathrm{~g}^{-1}\right)$ obtained in the absence and the presence of CD.

${ }^{\mathrm{b}} \mathrm{r}_{\mathrm{BA}}$ and $\mathrm{ee}_{\mathrm{BA}}$ are the initial rates $\left(\mathrm{mmol} \mathrm{h}^{-1} \mathrm{~g}^{-1}\right)$ and ee obtained in the presence of CD and $0.5 \mathrm{mmol} \mathrm{BA}$.

${ }^{c} \mathrm{r}_{\mathrm{BA}}$ and ee obtained at a reaction temperature of $275 \mathrm{~K}$ in the presence of BA as additive.

${ }^{\mathrm{d}}$ Conversions obtained in $8 \mathrm{~h}$ at $275 \mathrm{~K}$, using BA as additive.

In contrast, when the fluoro or methoxy group was situated in the ortho position on the $\alpha$-phenyl group in the presence of a para-methyl group on the $\beta$-phenyl ring (35 and 36), ee increased significantly, reaching slightly higher values than in the hydrogenations of $\mathbf{2}$ and $\mathbf{1 8}$ and significantly increased ee-s as compared with $\mathbf{3 1}$. These observation again supported the rationalization of the effects of the methoxy and fluoro substituents.

\subsection{Hydrogenations of acrylic acids bearing heteroaromatic substituents}

(E)-2-Phenyl-3-(2-furyl)propenoic acid (37) and (E)-2-(3-pyridyl)-3-phenylpropenoic acid (38) were prepared by Perkin condensation from the corresponding aromatic aldehydes and arylacetic acids, similarly as for the substituted (E)-2,3-diphenylpropenoic acids. The hydrogenations of these two 2,3-diphenylpropenoic acid analogues bearing heteroaromatic substituents (Scheme 21) were studied over a CD-modified Pd catalyst under reaction conditions identical with those for the compounds previously described.

The hydrogenations of these compounds over the unmodified catalyst in comparison with that of 1 are presented in Table 7, entries 1-3. The reactions were stopped when the $\mathrm{H}_{2}$ uptake ceased or slowed significantly. In the hydrogenations of $\mathbf{1}$ and $\mathbf{3 8}$, selective formation of the aryl-substituted propionic acids was observed at full conversions (see Figure 1). 


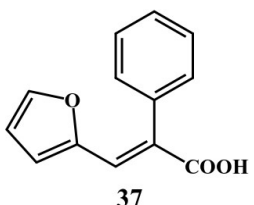

37<smiles>COC(=Cc1ccccc1)c1ccccc1</smiles>

38

\section{Scheme 21}

The (E)-diarylpropenoic acids

In contrast, in the hydrogenation of $\mathbf{3 7}$ the $\mathrm{H}_{2}$ consumption did not stop after the uptake of 1 equivalent of $\mathrm{H}_{2}$; after $6 \mathrm{~h}$, the product contained a significant amount $(36 \%)$ of the compound bearing a tetrahydrofuryl ring in a diastereomeric ratio of in 65:35 (Table 7, entries 1-3, and Scheme 22). The diastereomeric excess obtained showed that, at least in part, $3 \mathrm{H}_{2}$ was added to 37 without the desorption and consecutive re-adsorption of $\mathbf{3 7 a}$. This was also indicated by the fast $\mathrm{H}_{2}$ uptake up to about 1.4 equivalents, followed by a significant rate decrease (Figure 1). Thus, the geometry of the chiral centre formed by the addition of $1 \mathrm{H}_{2}$ could influence the stereochemistry of the saturation of the furyl ring.

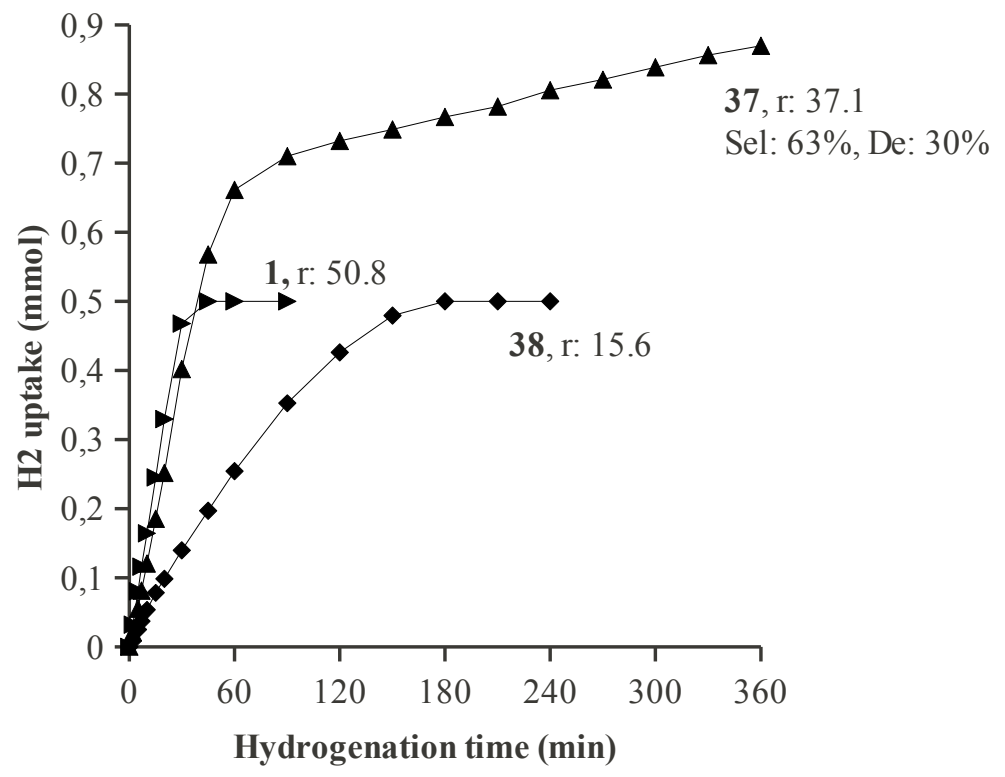

\section{Figure 1}

$\mathrm{H}_{2}$-uptake curves of the studied (E)-2,3-diphenylpropenoic acids over unmodified catalyst

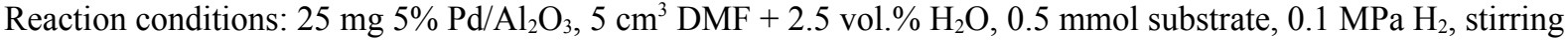
$1000 \mathrm{rpm}$; r: initial $\mathrm{H}_{2}$ uptake rate $\left(\mathrm{mmol} \mathrm{g}^{-1} \mathrm{~h}^{-1}\right)$, conversion $100 \%$; Sel: selectivity of the diarylpropionic acid $\mathbf{3 7 a}$; De: diastereoselectivity of the over hydrogenated product $\mathbf{3 7 b}$. 


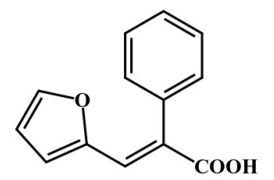

37

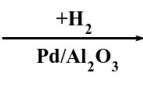

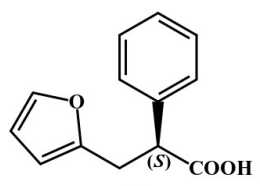

$37 \mathbf{a}$

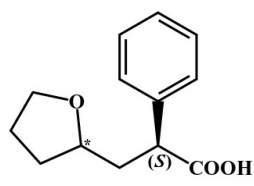

$37 \mathrm{~b}$

\section{Scheme 22}

Hydrogenation of (E)-2-phenyl-3-(2-furyl)propenoic acid over a Pd catalyst

The hydrogenation of the furyl ring can be explained on the basis of the hydrogenation experiments carried out with 2-furancarboxylic acid [93], and may be due to the relatively strong adsorption of this ring on the metal surface, which may also explain the lower initial rate obtained in the hydrogenation of $\mathbf{3 7}$ as compared with $\mathbf{1}$. The lowest rate observed in the hydrogenation of $\mathbf{3 8}$ may be interpreted as a consequence of the tilted steric arrangement of the aromatic ring in the $\alpha$ position relative to the cinnamic acid moiety, and the possible anchoring effect of the $\mathrm{N}$ atom, leading to the stronger adsorption of $\mathbf{3 8}$ and the corresponding saturated acid as compared with 1 and 2,3-diphenylpropionic acid, respectively. Tilted adsorption via the lone electron pair of an aromatic $\mathrm{N}$ atom over Pd surfaces has been demonstrated to occur even when a flat adsorption mode is possible, e.g. by the adsorption of pyridine, quinoline or quinoline moiety of cinchona alkaloids [86,87].

Results obtained in the hydrogenation of the three acids over the catalyst modified with CD are presented in Table 7, entries 4-6. In the presence of $\mathrm{CD}$, the initial rates decreased as compared with the racemic reactions. The acids bearing heteroaromatic substituents were hydrogenated at comparable rates, which were lower than that of $\mathbf{1}$. These hydrogenations afforded the corresponding 2,3-diarylpropenoic acids selectively; only a negligible amount of overhydrogenated product was formed even at close to the full conversion of $\mathbf{3 7}$. Accordingly, the saturated acid interacting with the modifier adsorbed on the Pd surface was replaced more easily by the unsaturated acid $\mathbf{3 7}$ as compared with the unmodified sites on which the adsorption of $\mathbf{3 7}$ and the saturated acid occurred, and also by bonding through the furyl ring leading to hydrogenation of this moiety. The product resulted in the same ee $(71 \%)$ as that from 1, while a much lower ee was obtained in the hydrogenation of $\mathbf{3 8}$.

The latter low ee may be attributed to the previously suggested anchoring effect of the pyridyl moiety, decreasing the rate of hydrogenation of $\mathbf{3 8}$ on modified sites too. Furthermore, the pyridyl moiety may also exert a hindering effect on the interaction with the adsorbed CD. 
Table 7

Hydrogenations of (E)-2,3-diarylpropenoic acids

\begin{tabular}{llccccccc}
\hline Entry & Substrate & $\begin{array}{c}\mathrm{CD} \\
(\mathrm{mmol})\end{array}$ & $\begin{array}{c}\mathrm{BA} \\
(\mathrm{mmol})\end{array}$ & $\begin{array}{c}\text { Temperature } \\
(\mathrm{K})\end{array}$ & $\begin{array}{c}\mathrm{r}^{\mathrm{a}} \\
\left(\mathrm{mmol} \mathrm{g}^{-1} \mathrm{~h}^{-1}\right)\end{array}$ & $\begin{array}{c}\text { Time } \\
(\mathrm{h})\end{array}$ & $\begin{array}{c}\mathrm{K} \\
(\%)\end{array}$ & $\begin{array}{c}\text { ee } \\
(\%)\end{array}$ \\
\hline 1 & $\mathbf{1}$ & - & - & 295 & 50.8 & 1.5 & 100 & - \\
2 & $\mathbf{3 7}$ & - & - & 295 & 37.1 & 6 & $100 / 63^{\mathrm{b}} / 30^{\mathrm{c}}$ & - \\
3 & $\mathbf{3 8}$ & - & - & 295 & 15.6 & 4 & 100 & - \\
4 & $\mathbf{1}$ & 0.025 & - & 295 & 8.6 & 6 & 100 & 71 \\
5 & $\mathbf{3 7}$ & 0.025 & - & 295 & 4.4 & 6 & $99 / 99^{\mathrm{b}}$ & 71 \\
6 & $\mathbf{3 8}$ & 0.025 & - & 295 & 5.4 & 6 & 100 & 46 \\
7 & $\mathbf{1}$ & 0.025 & 0.5 & 295 & 12.4 & 6 & 100 & 73 \\
8 & $\mathbf{3 7}$ & 0.025 & 0.5 & 295 & 6.4 & 6 & $96 / 98^{\mathrm{b}}$ & 71 \\
9 & & & & & & 18 & $100 / 95^{\mathrm{b}} / 0^{\mathrm{c}}$ & $71(60,59)^{\mathrm{d}}$ \\
10 & $\mathbf{3 8}$ & 0.025 & 0.5 & 295 & 8.4 & 5 & 100 & 61 \\
11 & $\mathbf{1}$ & 0.025 & 0.5 & 273 & 3.3 & 8 & 99 & 80 \\
12 & $\mathbf{3 7}$ & 0.025 & 0.5 & 273 & 2.1 & 8 & $75 />99^{\mathrm{b}}$ & 73 \\
13 & $\mathbf{3 8}$ & 0.025 & 0.5 & 273 & 3.2 & 8 & 100 & 54 \\
\hline
\end{tabular}

Reaction conditions: $25 \mathrm{mg} \mathrm{5 \%} \mathrm{Pd} / \mathrm{Al}_{2} \mathrm{O}_{3}{ }^{\mathrm{P}}, 5 \mathrm{~cm}^{3} \mathrm{DMF}+2.5$ vol. $\% \mathrm{H}_{2} \mathrm{O}, 0.5 \mathrm{mmol}$ substrate, $0.1 \mathrm{MPa}_{2}$

${ }^{\mathrm{a}}$ Initial rates of $\mathrm{H}_{2}$ uptake

${ }^{\mathrm{b}}$ Selectivity (\%) of the diarylpropionic acid $\mathbf{3 7 a}$.

${ }^{\mathrm{c}}$ Diastereomeric excess $(\%)$ of the side-products $\mathbf{3 7 b}$.

${ }^{\mathrm{d}}$ Enantiomeric excess (\%) of the diastereomers $\mathbf{3 7 b}$.

The addition of BA to the slurry increased the initial rates (Table 7, entries 7-10). However, differences in the effect of BA on ee were observed in the hydrogenation of these acids. Thus, no increase in ee was attained in the hydrogenation of $\mathbf{3 7}$, while in that of $\mathbf{3 8}$ ee increased by $15 \%$, much more than in the reaction of 1 . The effect of BA on ee was explained by the accelerated desorption of the hydrogenated product interacting with the adsorbed modifier [66]. Accordingly, the presence of BA increased the rate of hydrogenation of $\mathbf{3 7}$ to the same extent on both unmodified and modified sites, while in that of $\mathbf{3 8}$ a significant rate increase was preferentially obtained over modified sites. Extension of the hydrogenation time in the reaction of $\mathbf{3 7}$ to $18 \mathrm{~h}$ resulted in only a small amount of overhydrogenated product. The diastereomers of $\mathbf{3 7 \mathbf { b }}$ were formed in equal amounts, both in an enantiomeric ratio of 80:20, ee values reaching close to that of the hydrogenated product 37a. Accordingly, following the hydrogenation of the olefinic double bond, the molecule is desorbed from modified sites and the hydrogenation of 37a occurs by re-adsorption of this acid. This second hydrogenation step was not directed by the chiral centre formed in the first step due to the 
flexible $-\mathrm{CH}_{2}$ - link between the chiral centre and the furyl moiety resulting in lack of diastereoselectivity and close to maintained enantiomeric ratios.

On decrease of the hydrogenation temperature, 37 behaved according to expectations, while the hydrogenation of $\mathbf{3 8}$ at low reaction temperature resulted in a lower ee as compared with the room temperature reaction (Table 7, entries 11-13) This result also supported our assumption relating to the anchoring effect of the pyridyl moiety on both unmodified and chiral sites.

\subsection{Hydrogenations of $\alpha, \beta$-unsaturated carboxylic acids in a high-pressure continuous-} flow system using a fixed-bed reactor

The enantioselective hydrogenations of four $\alpha, \beta$-unsaturated carboxylic acids were studied over a CD-modified supported Pd catalyst in a high-pressure continuous-flow system using a fixed-bed reactor. The unsaturated carboxylic acids $(E)$-2,3-diphenylpropenoic acid (1, 98\%, Aldrich), (E)-2-methyl-2-butenoic acid (39, 98\%, Aldrich), (E)-2-methyl-2-hexenoic acid (40, 98\%, Alfa Aesar) and itaconic acid (41, $\geq 99 \%$, Fluka) were used without purification.

\subsubsection{Hydrogenation procedures and product analysis}

Continuous hydrogenations were carried in an H-Cube high-pressure continuous-flow system purchased from Thales Nanotechnology Inc. [140]. For each run, $300 \pm 10 \mathrm{mg} 5 \%$ $\mathrm{Pd} / \mathrm{Al}_{2} \mathrm{O}_{3}$ catalyst was filled in a tubular catalyst cartridge $4 \mathrm{~mm}$ in inner diameter and $30 \mathrm{~mm}$ long. The cartridge was placed vertically in the cartridge holder. The catalyst was rinsed for $0.5 \mathrm{~h}$ in a $1 \mathrm{~cm}^{3} \mathrm{~min}^{-1}$ flow of solvent, followed by a $0.5 \mathrm{~h}$ pretreatment with $\mathrm{H}_{2}$ in the same solvent. The reactant, modifier and achiral additive were dissolved in the desired solvent and this solution was delivered to the hydrogenation system via a conventional HPLC pump (Knauer WellChrom HPLC-pump K-120), $\mathrm{H}_{2}$ being mixed into the liquid flow under the desired pressure (0.1-5 MPa) in the mixer of the apparatus. The catalyst cartridge holder was equipped with an externally controlled cooling jacket. The mixture was pumped through the catalyst bed to obtain an ascending flow of the reaction components. At regular time intervals, samples of $1 \mathrm{~cm}^{3}$ were taken from the product and analyzed. The hydrogenation of $\mathbf{4 0}$ in a batch reactor was carried out under $5 \mathrm{MPa}_{2}$ pressure in a stainless steel autoclave equipped with a Teflon liner. In a typical run, $25 \mathrm{mg}$ catalyst and $10 \mathrm{~cm}^{3}$ toluene were loaded into the 
reactor, followed by pretreatment of the catalyst by stirring $(1000 \mathrm{rpm})$ of the slurry at $295 \mathrm{~K}$ under $\mathrm{H}_{2}$ for $30 \mathrm{~min}$. After this pretreatment, the desired amount of $\mathrm{CD}$ and $1 \mathrm{mmol}$ of $\mathbf{4 0}$ were introduced, the system was flushed with $\mathrm{H}_{2}$, the pressure was set to $5 \mathrm{MPa}$ and the mixture was stirred for $1 \mathrm{~h}$. Finally, the catalyst was filtered off and the products were analyzed.

The products formed in the hydrogenations of 39 and $\mathbf{4 0}$ were washed with $2 \mathrm{~N} \mathrm{HCl}$ solution, while those from in the hydrogenations of $\mathbf{1}$ and $\mathbf{4 1}$ were transformed to methyl esters with cc. $\mathrm{H}_{2} \mathrm{SO}_{4}$ in methanol prior to analysis. Products were identified by GC-MS analysis. Conversions and ee were determined by GC analysis, using the HP 5890 II GC-FID and chiral capillary columns (HP-Chiral, $30 \mathrm{~m}$ for $\mathbf{3 9}$ and 40; or Cyclosil-B, $30 \mathrm{~m}$ for $\mathbf{1}$ and 41). Ee was calculated with the formula given in section 3.2.1. The absolute configurations of the excess enantiomers were known from previous studies $[68,82]$.

\subsubsection{Hydrogenations of (E)-2-methyl-2-butenoic and (E)-2-methyl-2-hexenoic acids}

Results obtained in the continuous hydrogenations of the aliphatic unsaturated acids 39 and 40 are presented in Figures 2 and 3, respectively. The reactions were performed in toluene under high $(5 \mathrm{MPa}) \mathrm{H}_{2}$ pressure according to the results obtained in the batch reactors $[68,74]$.

Both acids were transformed completely under the experimental conditions used. Introduction of $\mathrm{CD}$ into the feed resulted in the formation of optically enriched products with ee-s of $44 \%$ and $51 \%$, respectively. These values were only slightly lower than those obtained in the batch reactor under similar reaction conditions [68]. The addition of BA increased the optical purities of the products obtained in the fixed-bed reactor, too. Thus, in the hydrogenation of 39, 0.5 equivalent BA increased ee up to $50 \%$. Increase of the amount of the additive to 1 equivalent was prevented by crystallization of the benzylammonium salt of $\mathbf{3 9}$ in toluene. However, in the hydrogenation of $\mathbf{4 0}$, crystallization did not occur and increase of the amount of BA to 1 equivalent resulted in a further increase in ee, from $56 \%$ to $60 \%$. It is important that the ee-s did not alter during the time on stream in the time frame studied. 


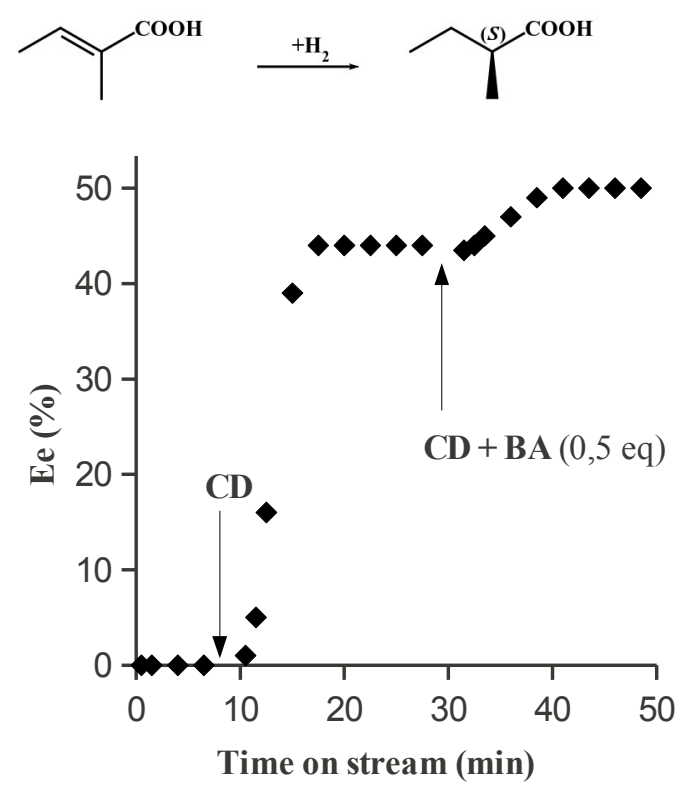

Figure 2

Hydrogenation of 39 in a fixed-bed reactor over a $\mathrm{Pd} / \mathrm{Al}_{2} \mathrm{O}_{3}$ catalyst

Reaction conditions: $5 \mathrm{MPa} \mathrm{H}_{2}, 283 \pm 2 \mathrm{~K}$, liquid flow rate $1 \mathrm{ml} \mathrm{min}^{-1}$, solvent toluene, 39: concentration $50 \mathrm{mM}$; the arrows indicate the times when $\mathrm{CD}(2.5 \mathrm{mM})$ and BA $(25 \mathrm{mM})$ were introduced into the feed.
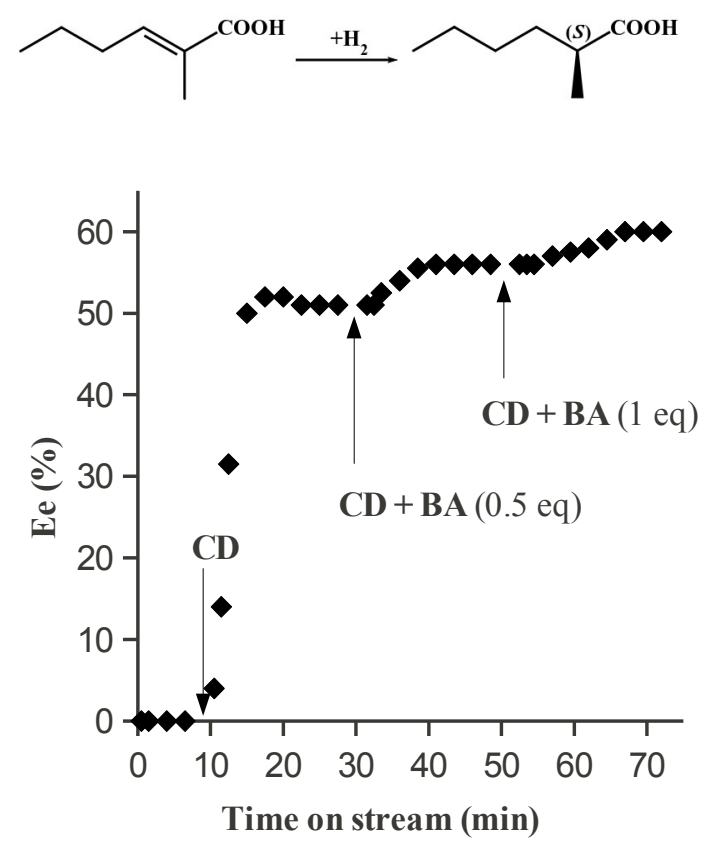

Figure 3.

Hydrogenation of $\mathbf{4 0}$ in a fixed-bed reactor over a $\mathrm{Pd} / \mathrm{Al}_{2} \mathrm{O}_{3}$ catalyst

Reaction conditions: $5 \mathrm{MPa} \mathrm{H}_{2}, 283 \pm 2 \mathrm{~K}$, liquid flow rate $1 \mathrm{ml} \mathrm{min}^{-1}$, solvent toluene, 40: concentration 50 $\mathrm{mM}$; the arrows indicate the times when $\mathrm{CD}(2.5 \mathrm{mM})$ and BA $(25$ and $50 \mathrm{mM})$ were introduced into the feed. 


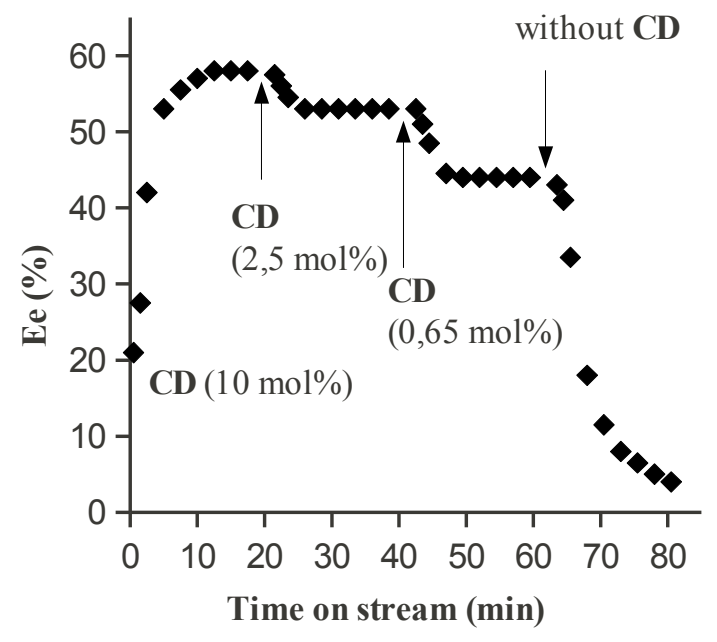

Figure 4

Hydrogenation of $\mathbf{4 0}$ in a fixed-bed reactor over a $\mathrm{Pd} / \mathrm{Al}_{2} \mathrm{O}_{3}$ catalyst

For the reaction conditions, see Figure 2; 40: concentration $50 \mathrm{mM}$; BA concentration $50 \mathrm{mM}$; the arrows indicate the times when the concentration of $\mathrm{CD}$ was changed (concentration values relative to $\mathbf{4 0}$ are given in parenthesis).

The relatively high amounts of modifier used in these experiments ( $5 \mathrm{~mol} \%)$ prompted us to examine the necessity of using such amounts by decreasing the CD concentration. The experiment was carried out with $\mathbf{4 0}$ in the presence of 1 equivalent of BA and an initial $10 \mathrm{~mol} \%$ of CD (Figure 4). Ee increased in the first $12 \mathrm{~min}$ to a constant value, i.e. 58\%. On decrease of the CD amount to 2.5 and $0.65 \mathrm{~mol} \%$, ee decreased to $53 \%$ and $44 \%$. Following modifications in the CD concentration, ee reached constant values in a few minutes and these values persisted until the next change of the modifier concentration. When the CD feed was stopped, ee decreased rapidly, leading to a nearly racemic product after an additional $20 \mathrm{~min}$ flow.

\subsubsection{Hydrogenations of (E)-2,3-diphenylpropenoic acid and itaconic acid}

The highest ee values in this catalytic system were obtained in the hydrogenations of $\mathbf{1}$ and its substituted derivatives. Accordingly, we continued our studies in a fixed-bed reactor with the hydrogenation of $\mathbf{1}$. Similar reaction conditions were chosen to those providing high ee-s in the slurry reactor $[66,71,74]$. However, in order to avoid crystallization of the saturated acid salt in the presence of BA, we used methanol as solvent. Introduction of CD into the feed resulted in good ee (61-62\%) 1 concentrations of both 50 and $100 \mathrm{mM}$ (Figure 5). These values were higher than in the hydrogenation of the same acid in methanol in the batch reactor [66]. 

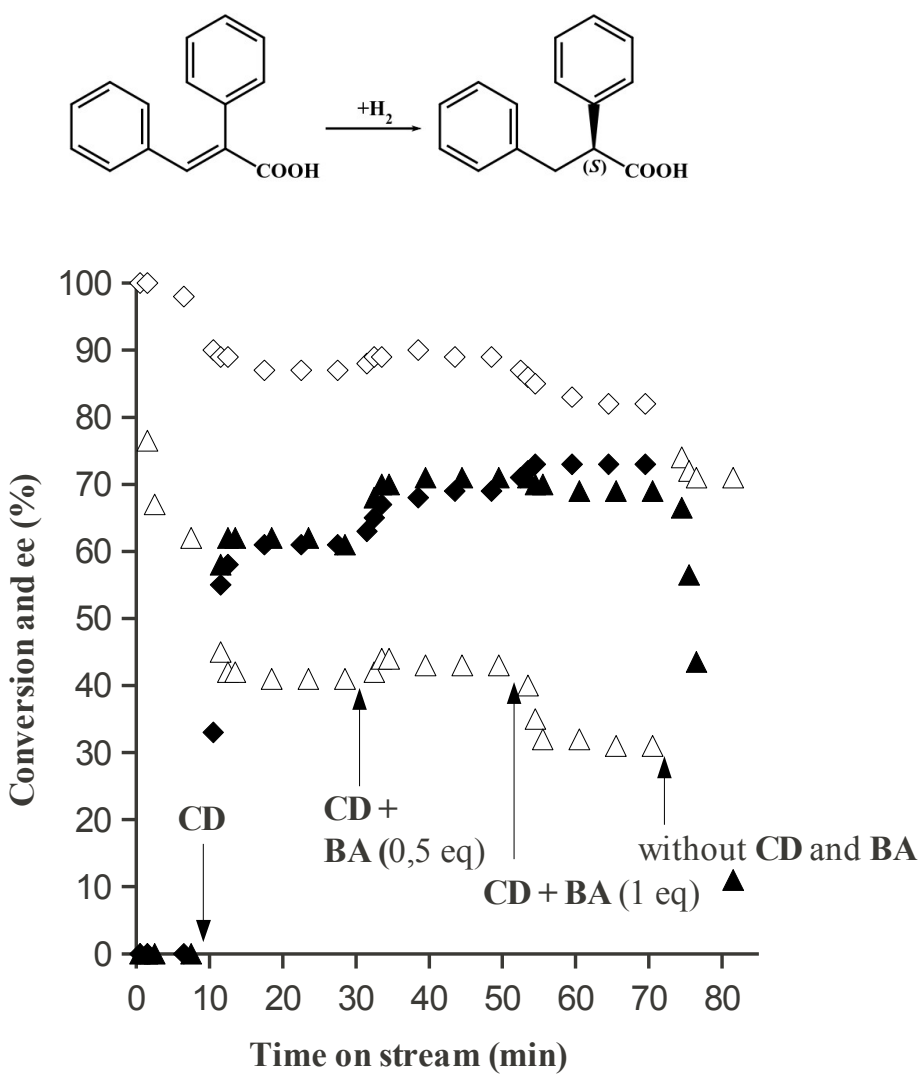

Figure 5

Conversion (open symbols) and ee (filled symbols) in the hydrogenation of $\mathbf{1}$ in a fixed-bed reactor over a $\mathrm{Pd} / \mathrm{Al}_{2} \mathrm{O}_{3}$ catalyst

Reaction conditions: $0.1 \mathrm{MPa} \mathrm{H}_{2}, 283 \pm 2 \mathrm{~K}$, liquid flow rate $1 \mathrm{ml} \mathrm{min}^{-1}$, solvent methanol, 1, CD and BA concentrations: $50 \mathrm{mM}, 2.5 \mathrm{mM}$ and $25-50 \mathrm{mM}$ (diamonds); $100 \mathrm{mM}, 5 \mathrm{mM}$ and 50-100 mM (triangles); the arrows indicate changes of the $\mathrm{CD}$ and/or BA concentrations in the feed.

A significant conversion decrease was observed as an effect of the presence of $\mathrm{CD}$ when the $100 \mathrm{mM}$ solution was reacted. Addition of 0.5 equivalent BA to the feed increased ee to $70 \%$ in both experiments. Further increase of the BA amount to 1 equivalent had a beneficial effect on ee only when a lower concentration of 1 was used (ee 73\%). Interestingly, in both experiments the conversions increased on the addition of 0.5 equivalent $\mathrm{BA}$, but decreased in the presence of 1 equivalent BA. The decrease in conversion was clearly not the result of irreversible poisoning of the metal surface, as cessation of the $\mathrm{CD}$ and $\mathrm{BA}$ feed resulted not only in a sudden decrease in ee, but also in similar conversions as obtained over the unused catalyst.

These results on the hydrogenation of $\mathbf{1}$ in a fixed-bed reactor indicated that similar ee-s can be obtained as in slurry reactors under similar conditions. Furthermore, some novel details of the hydrogenation of this carboxylic acid were observed. Thus, the effect of BA on the 
reaction rate was highly dependent on the relative amount of BA and the effect of 1 equivalent additive on ee was influenced by the concentration of the substrate.

The results obtained in the hydrogenation of $\mathbf{4 1}$ in a continuous-flow system under $2 \mathrm{MPa} \mathrm{H}_{2}$ pressure are shown in Figure 6. The reaction conditions ensured the complete transformation of 41. The low ee obtained with CD increased significantly, up to $26 \%$, in the presence of 1 equivalent BA, and exceeded $40 \%$ on the addition of 2 equivalent of the achiral organic base.

The above results demonstrated that the enantioselective hydrogenations of $\alpha, \beta$ unsaturated carboxylic acids over Pd catalysts in the presence of cinchona alkaloids are applicable for the production of optically enriched carboxylic acids in a continuous-flow system. It was also shown that the beneficial effect of BA on ee is maintained in the flow system. The optical purities of the products obtained from aliphatic unsaturated carboxylic acids $(39,40$ and 41) were usually slightly lower than in the batch reactors. These results were obtained at full conversions and the same modifier concentrations (relative to the substrates) as used in the slurry reactors. Furthermore, the effect of the $C D$ concentration in the hydrogenation of $\mathbf{4 0}$ was similar to the effect of $\mathrm{CD}$ in the batch hydrogenation of this acid (Figure 7), a trend usually observed in the hydrogenations of these types of substrates [78]. Thus, in the continuous enantioselective hydrogenation of $\alpha, \beta$-unsaturated carboxylic acids, it was not necessary to use modifier/reactant ratios as high as usually needed in slurry reactors.

As the aliphatic substrates were transformed completely, the reaction may be controlled by diffusion. Further studies are necessary to reveal the reaction conditions that fully exploit the potential of the flow system in these reactions. In view of the conditions ensuring full conversion, it is not possible to calculate precise production rates in the hydrogenations of these compounds. However, we have ascertained that these saturated carboxylic acids can be obtained at a production rate of at least $10 \mathrm{mmol} \mathrm{g}_{\mathrm{cat}}{ }^{-1} \mathrm{~h}^{-1}$, a value of the same order of magnitude as that obtained in the hydrogenation of ethyl pyruvate [114]. In the hydrogenation of 1, a 2-fold increase of the substrate concentration led to a decrease of a 2-fold in the conversion over the modified catalyst. Accordingly, at a higher concentration of $\mathbf{1}$, the reaction was free of external diffusion control. Under these conditions, it was possible to obtain (S)-2,3-diphenylpropionic acid in 70\% optical purity with a production rate of $8.6 \mathrm{mmol} \mathrm{g}_{\text {cat }}{ }^{-1} \mathrm{~h}^{-1}$. 


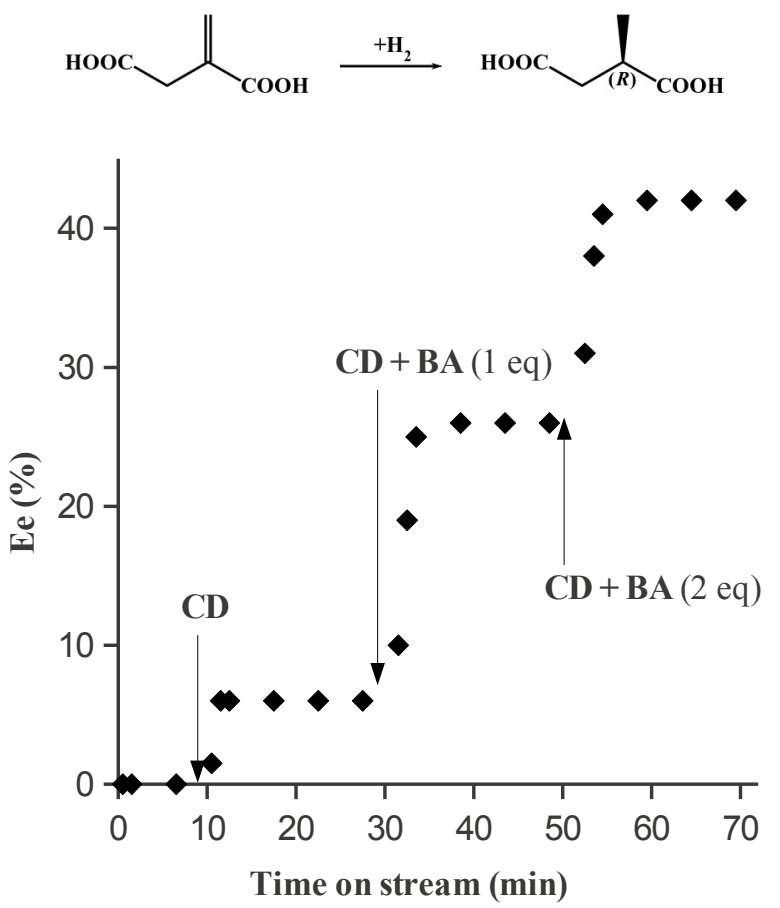

Figure 6

Hydrogenation of $\mathbf{4 1}$ in a fixed-bed reactor over a $\mathrm{Pd} / \mathrm{Al}_{2} \mathrm{O}_{3}$ catalyst

Reaction conditions: $2 \mathrm{MPa} \mathrm{H}_{2}, 283 \pm 2 \mathrm{~K}$, liquid flow rate $1 \mathrm{ml} \mathrm{min}^{-1}$, solvent methanol, 41: concentration $50 \mathrm{mM}$; the arrows indicate the times when $\mathrm{CD}(2.5 \mathrm{mM})$ and $\mathrm{BA}(50$ and $100 \mathrm{mM})$ were introduced into the feed.

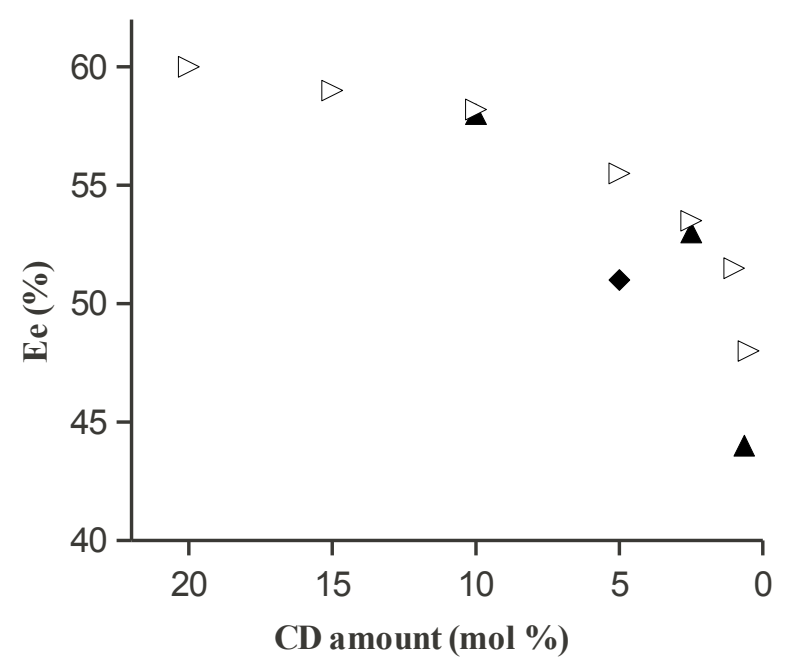

Figure 7

Effects of CD concentration on the enantioselectivity in the hydrogenation of $\mathbf{4 0}$ in batch (open triangles) and fixed-bed (without BA (filled diamonds)); using 1 equivalent BA (filled triangles) reactors

For the reaction condition, see Figures 2 and 3. 
There is an intense ongoing debate in the literature on the mechanism of enantioselective hydrogenation over cinchona-modified metal catalysts. In the hydrogenations of $\alpha$-keto esters over $\mathrm{Pt}$, the formation of an intermediate complex on the metal surface is accepted, involving interaction of the adsorbed cinchona alkaloid and the substrate. In the hydrogenations of $\alpha, \beta$-unsaturated carboxylic acids, it is known that aliphatic acids form 2:1 acid-cinchona complexes [74,76,78], while the intermediates formed in the hydrogenations of 1 and $\mathbf{4 1}$ in polar solvents have a 1:1 composition [60,90]. The sudden drop in ee on decrease of the CD concentration or cessation of its feed (Figures 4 and 5) showed that a high concentration of chiral auxiliary is necessary in the liquid phase to obtain good enantioselectivity. It also demonstrated that the adsorbed modifier was readily desorbed if was not added to the feed. Desorption was accelerated by the continuous substrate flow, due to the interaction of the acid with the adsorbed modifier. These were confirmed by the identical conversions obtained in the racemic hydrogenation of $\mathbf{1}$ that followed enantioselective hydrogenation and in the racemic hydrogenation over fresh catalyst (Figure 5). Similarly, the adsorbed modifier may also be continuously exchanged during the reaction on the surface. It is known from previous studies that at low coverage the CD flatly adsorbed on the Pd surface has a much higher mobility than on $\mathrm{Pt}$, and at increasing coverage the additional cinchona alkaloid is weakly adsorbed through the quinoline $\mathrm{N}$, tilted with respect to the Pd surface $[86,87]$. Thus, it is reasonable to assume that, under our experimental conditions (high modifier concentration), the adsorption strength of the modifier is smaller than that of a modifier-acid complex. This suggests that the interaction of the unsaturated acid with the modifier occurs in the liquid phase, the salt-like complex is adsorbed on the surface and the modifier-saturated acid desorbs.

In the presence of BA, the interaction between the hydrogenated product and the cinchona alkaloid on the surface is weakened by the interaction of the product with BA. Desorption of the product-BA salt will either leave the modifier adsorbed on the surface and will hinder racemic hydrogenation, or will facilitate desorption of the whole CD-saturated acid complex. However, the participation of BA in the formation of the surface intermediate complex cannot be excluded. In the hydrogenations of the aliphatic substrates, the beneficial effect of the adsorbed BA by occupying racemic metal sites, as suggested by the batch hydrogenation results on 41 [90], may also a play role in obtaining high ee-s values. The composition and the structure of the surface intermediate in the presence of BA will be studied in the near future using both batch and fixed-bed reactors. 


\section{SUMMARY}

1. We have studied the effects of the position of the methoxy substituent position on the initial rate and the enantioselectivity in the hydrogenations of mono- and dimethoxysubstituted 2,3-diphenylpropenoic acids over a cinchonidine-modified supported Pd catalyst in the absence and in the presence of benzylamine as additive. The results obtained cannot be interpreted solely in terms of the electronic effects of the substituents. Depending on the substituent position, the steric effects may become a dominant factor. This was indicated by the opposite effects on the initial rate and ee of the 2-methoxy substituents situated on the $\alpha$ and $\beta$-phenyl rings, the former increasing, and the latter significantly decreasing the optical purity of the resulting saturated products. The highest ee-s (up to 92\%) were obtained in the hydrogenation of (E)-2-(2-methoxyphenyl)-3-(4-methoxyphenyl)propenoic acid, due to the combined favourable steric and electronic effects of the substituent on the $\alpha$ - and $\beta$-phenyl rings.

2. The enantioselective hydrogenations of methoxy-, fluoro- and methyl-substituted $(E)$ 2,3-diphenylpropenoic acid derivatives were investigated under the same reaction conditions. The results showed that a fluoro substituent in some positions may be as efficient as or even more efficient than the methoxy group in increasing the optical purity of the saturated products. Ee-s up to $96 \%$ were obtained in the hydrogenations of prochiral unsaturated carboxylic acids over modified heterogeneous catalysts. The highest ee-s were reached in the hydrogenations of derivatives bearing a para substituent on the $\beta$-phenyl and an ortho substituent on the $\alpha$-phenyl ring. The substituent on the $\beta$-phenyl ring influenced ee through its electronic effect and its effect on the adsorption strength on the Pd surface. Thus, an electron-releasing substituent decreased the acidity of the substrate and consequently increased the interaction efficiency with the modifier. A substituent in this position which decreased the adsorption strength of the acid may also lead to an increase in ee by increasing the hydrogenation rate on the modifier sites. The beneficial effect of the ortho substituent on the $\alpha$-phenyl ring was not related to its electronic effect, and only in small part to its steric effect. We assumed that the increased ee was due to the ability of the methoxy or fluoro substituents to form additional interactions with the modifier on the surface. These suggestions were supported by results obtained in the hydrogenations of several methylsubstituted derivatives. 
3. The hydrogenations of two 2,3-diarylpropenoic acid bearing heteroaromatic substituents over a CD-modified Pd catalyst resulted in the enantioselective formation of the corresponding diarylpropionic acids. The 2-furyl-substituted compound was selectively hydrogenated to 2-phenyl-3-(2-furyl)propionic acid in the presence of modifier with up to $73 \%$ ee, although over the unmodified catalyst the furyl moiety was hydrogenated simultaneously with the olefinic double bond. The hydrogenation of the acid bearing a 3pyridyl substituent in the $\alpha$ position afforded a lower ee as compared with the compound with a phenyl substituent in the same position. The addition of BA proved to have a beneficial effect on ee in the hydrogenation of the latter compound, whereas decrease of the reaction temperature resulted in a decrease in ee, in contrast with the other acids studied to date in this catalyst system. The results obtained were interpreted in terms of the probable effects of the heteroaromatic rings on the strengths and modes of adsorption of these acids and the modifications in the interaction strengths with the adsorbed CD.

4. We examined the enantioselective hydrogenations of four $\alpha, \beta$-unsaturated carboxylic acids, (E)-2,3-diphenylpropenoic acid, (E)-2-methyl-2-butenoic acid, (E)-2-methyl-2hexenoic acid and itaconic acid, over CD-modified $\mathrm{Pd} / \mathrm{Al}_{2} \mathrm{O}_{3}$ catalyst in an $\mathrm{H}$-Cube continuous-flow system using a fixed-bed reactor. The hydrogenations of the aliphatic substrates resulted in products with ee-s slightly lower than those obtained in batch reactors under similar reaction conditions. The optical purity of the product formed in the hydrogenation of $(E)$-2,3-diphenylpropenoic acid was over $70 \%$, exceeding that obtained in the same solvent in the slurry reactor. The ee-increasing effect of BA persisted in the fixedbed reactor. From the results obtained by changing the modifier concentration in the feed, we suggest that the interactions of the substrates with CD may occur in the liquid phase and the complexes formed are adsorbed on the Pd surface. Thus, relatively high concentrations of such complexes and modifiers are necessary to obtain good ee-s in the hydrogenations of $\alpha, \beta$ unsaturated carboxylic acids. 


\section{REFERENCES}

1. E. Francotte, W. Lindner (Eds.), Chirality in Drug Research, Wiley-VCH, Weinheim, 2006.

2. M. Breuer, K. Ditrich, T. Habicher, B. Hauer, M. Kesseler, R. Stürmer, T. Zelinski, Angew. Chem. Int. Ed. 2004, 43, 788.

3. J. A. F. Boogers, U. Felfer, M. Kotthaus, L. Lefort, G. Steinbauer, A. H. M. De Vries, J. G. De Vries, Org. Proc. Res. Dev. 2007, 11, 585.

4. H. -U. Blaser, E. Schmidt (Eds.) Asymmetric Catalysis on Industrial Scale. Challenges, Approaches and Solutions, Wiley-VCH, Weinheim, 2004.

5. H. -U. Blaser, C. Malan, B. Pugin, F. Spindler, H. Steiner, M. Studer, Adv. Synth. Catal. 2003, 345, 103.

6. H. -U. Blaser, B. Pugin, F. Spindler, J. Mol. Catal. A: Chem. 2005, 231, 1.

7. T. Ohkuma, M. Kitamura, R. Noyori, in: I. Ojima (Ed.), Catalytic Asymmetric Synthesis, $2^{\text {nd }}$ ed., Wiley-VCH, New York, 2000, p. 1 (Chap. 1.)

8. W. S. Knowles, Angew. Chem. Int. Ed. 2002, 41, 1998.

9. R. Noyori, Angew. Chem. Int. Ed. 2002, 41, 2008.

10. C. Jakel, R. Paciello, Chem. Rev. 2006, 106, 2912.

11. K. Mikami, Y. Itoh, M. Yamanaka, Chem. Rev. 2004, 104, 16.

12. J. -A. Ma, D. Cahard, Chem. Rev. 2004, 104, 6119.

13. H. Ibrahim, A. Togni, Chem. Commun. 2004, 1147.

14. M. Oestreich, Angew. Chem. 2005, 117, 2376.

15. T. Ohkuma, M. Koizumi, H. Doucet, T. Pham, M. Kozawa, K. Murata, E. Katayama, T. Yokozawa, T. Ikariya, R. Noyori, J. Am. Chem. Soc. 1998, 120, 13529.

16. F. Turek, R. K. Chakrabarti, R. Lange, R. Geike, W. Flock, Chem. Eng. Sci. 1983, 38, 275.

17. P. Gallezot, N. Nicolaus, G. Fleche, P. Fuertes, A. Perrard, J. Catal. 1998, 180, 51.

18. A. R. Bogdan, B. P. Mason, K. T. Sylvester, D. T. McQuade, Angew. Chem. Int. Ed. 2007, 46, 1698.

19. D.E. De Vos, I.F.J. Vankelecom, P.A. Jacobs (Eds.), Chiral Catalyst Immobilization and Recycling, Wiley-VCH, Weinheim, 2000.

20. M. Studer, H. -U. Blaser, C. Exner, Adv. Synth. Catal. 2003, 345, 45.

21. D. Y. Murzin, P. Mäki-Arvela, E. Toukoniitty, T. Salmi, Catal. Rev. Sci. Eng. 2005, 47, 175.

22. T. Mallat, E. Orglmeister, A. Baiker, Chem. Rev. 2007, 107, 4863.

23. H. Brunner, W. Zettlemeyer, Handbook of Enantioselective Catalysis with Transition Metal Compounds, VCH: Weinheim, 1993.

24. R. Noyori, Asymmetric Catalysis in Organic Synthesis, Wiley-VCH: New York, 1994.

25. R. A. Sheldon, Chyrotechnology, Marcel Dekker: New York, 1993.

26. C. Bolm, Chem. Rev., 2003, 103, 2361.

27. D. Enders, K. -E. Jaeger, Asymmetric Synthesis with Chemical and Biological Methods, Wiley-VCH: Weinheim, 2007.

28. I. Ojima, Catalytic Asymmetric Synthesis, Sec. Ed., John Wiley \& Sons: New York, 2000.

29. K. B. Sharpless, Angew. Chem. Int. Ed. 2002, 41, 2024. 
30. J. M. Thomas, R. Raja, D. W. Lewis, Angew. Chem. Int. Ed. 2005, 44, 6456.

31. M. Heitbaum, F. Glorius, I. Escher, Angew. Chem. Int. Ed. 2006, 45, 4732.

32. Á. Zsigmond, F. Notheisz, Curr. Org. Chem. 2006, 10, 1655.

33. A. Crosman, W. F. Hoelderich, Catal. Today 2007, 121, 130.

34. Y. Izumi, M. Imaida, H. Fukawa, S. Akabori, Bull. Chem. Soc. Jpn. 1963, 36, 155.

35. T. Sugimura, S. Nakagawa, A. Tai, Bull. Chem. Soc. Jpn. 2002, 75, 355.

36. T. Osawa, T. Harada, O. Takayasu, Curr. Org. Chem. 2006, 10, 1513.

37. Y. Orito, S. Imai, S. Niwa, Nippon Kagaku Kaishi 1979, 1118.

38. Y. Orito, S. Imai, S. Niwa, Nippon Kagaku Kaishi 1980, 670.

39. K. Szőri, M. Sutyinszki, K. Felföldi, M. Bartók, Appl. Catal. A: Gen. 2002, 237, 275.

40. M. Bartók, Curr. Org. Chem. 2006, 10, 1533.

41. A. Tungler, É. Sípos, V. Háda, ARKIVOC 2004, (vii) 223.

42. A. Tungler, É. Sípos, V. Háda, Curr. Org. Chem. 2006, 10, 1569.

43. W.-R. Huck, T. Mallat, A. Baiker, New J. Chem. 2002, 26, 6.

44. K. Szőri, Gy. Szőllősi, K. Felföldi, M. Bartók, React. Kinet. Catal. Lett. 2005, 84, 151.

45. G. Fogassy, A. Tungler, A. Lévai, J. Mol. Catal. A: Chem. 2003, 192, 189.

46. G. Farkas, K. Fodor, A. Tungler, T. Máthé, G. Tóth, R. A. Sheldon, J. Mol. Catal A: Chem. 1999, 138, 123.

47. A. Tungler, T. Máthé, J. Petró, T. Tarnai, J. Mol. Catal. 1990, 61, 259.

48. S. C. Mhadgut, M. Török, J. Esquibel, B. Török, J. Catal. 2006, 238, 441.

49. É. Sípos, A. Tungler, React. Kinet. Catal. Lett. 2003, 80, 365.

50. É. Sípos, A. Tungler, I. Bitter, J. Mol. Catal. A: Chem. 2003, 198, 167.

51. R. E. Padgett Jr., R. L. Beamer, J. Pharm. Sci. 1964, 53, 689.

52. H. -U. Blaser, Tetrahedron: Asymmetry 1991, $2,843$.

53. Q. -H. Xia, S. -C. Shen, J. Song, S. Kawi, K. Hidajat, J. Catal. 2003, 219, 74.

54. M. Bartók, Gy. Wittmann, G. B. Bartók, Gy. Göndös, J. Organomet. Chem. 1990, 384, 385.

55. J. R. G. Perez, J. Malthete, J. Jacques, C. R. Acad. Sci. Paris Ser. II 1985, 300, 169.

56. Y. Nitta, Y. Ueda, T. Imanaka, Chem. Lett. 1994, 1095.

57. Y. Nitta, K. Kobiro, Chem. Lett. 1995, 165.

58. Y. Nitta, K. Kobiro, Chem. Lett. 1996, 897.

59. Y. Nitta, K. Kobiro, Y. Okamoto, Stud. Surf. Sci. Catal. 1997, 108, 191.

60. Y. Nitta, A. Shibata, Chem. Lett. 1998, 161.

61. Y. Nitta, Y. Okamoto, Chem. Lett. 1998, 27, 1115.

62. Y. Nitta, T. Kubota, Y. Okamoto, Bull. Chem. Soc. Jpn. 2000, 73, 2635.

63. Y. Nitta, Bull. Chem. Soc. Jpn. 2001, 74, 1971.

64. Y. Nitta, T. Kubota, Y. Okamoto, Bull. Chem. Soc. Jpn. 2001, 74, 2161.

65. Y. Nitta, Chem. Lett. 1999, 635.

66. Y. Nitta, Topics Catal. 2000, 13, 179.

67. A. Tungler, Y. Nitta, K. Fodor, G. Farkas, T. Máthé, J. Mol. Catal. A: Chem. 1999, 149, 135.

68. Gy. Szőllősi, S. Niwa, T. Hanaoka, F. Mizukami, J. Mol. Catal. A: Chem. 2005, 230, 91.

69. K. Borszeky, T. Mallat, A. Baiker, Tetrahedron: Asymmetry 1999, 10, 4781.

70. T. Sugimura, J. Watanabe, T. Okuyama, Y. Nitta, Tetrahedron: Asymmetry 2005, 16, 
1573

71. Y. Nitta, J. Watanabe, T. Okuyama, T. Sugimura, J. Catal. 2005, 236, 164.

72. T. Sugimura, J. Watanabe, T. Uchida, Y. Nitta, T. Okuyama, Catal. Lett. 2006, 112, 27.

73. T. J. Hall, P. Johnston, W. A. H. Vermeer, S. R. Watson, P. B. Wells, Stud. Surf. Sci. Catal. 1996, 101, 221.

74. K. Borszeky, T. Mallat, A. Baiker, Catal. Lett. 1996, 41, 199.

75. K. Borszeky, T. Mallat, A. Baiker, Tetrahedron: Asymmetry 1997, 8, 3745.

76. K. Borszeky, T. Bürgi, Z. Zhaohui, T. Mallat, A. Baiker, J. Catal. 1999, 187, 160.

77. K. Borszeky, T. Mallat, A. Baiker, Catal. Lett. 1999, 59, 95.

78. I. Kun, B. Török, K. Felföldi, M. Bartók, Appl. Catal. A: Gen. 2000, 203, 71.

79. A. Solladié-Cavallo, F. Hoernel, M. Schmitt, F. Garin, J. Mol. Catal. A: Chem. 2003, $195,181$.

80. R. Bisignani, S. Franceschini, O. Piccolo, A. Vaccari, J. Mol. Catal. A: Chem. 2005, 232,161 .

81. M. Casagrande, S. Fraceschini, M. Lenarda, O. Piccolo, A. Vaccari, J. Mol. Catal. A: Chem. 2006, 246, 263.

82. Gy. Szöllösi, T. Hanaoka, S. Niwa, F. Mizukami, M. Bartók, J. Catal. 2005, 231, 480.

83. D. Ferri, T. Bürgi, A. Baiker, J. Chem. Soc., Perkin Trans. 2. 1999, 1305.

84. D. Ferri, T. Bürgi, A. Baiker, J. Chem. Soc., Perkin Trans. 2. 2002, 437.

85. T. Bürgi, A. Baiker, J. Am. Chem. Soc. 1998, 120, 12920.

86. D. Ferri, T. Bürgi, A. Baiker, J. Catal. 2002, 210, 160.

87. M. Wahl, M. von Arx, T. A. Jung, A. Baiker, J. Phys. Chem. B 2006, 110, 21777.

88. J. T. Kiss, K. Felföldi, I. Hannus, I. Pálinkó, J. Mol. Struct. 2001, 565-566, 463.

89. M. B. Gordon, E. A. Yerger, J. Am. Chem. Soc. 1954, 76, 5211.

90. Gy. Szőllősi, K. Balázsik, M. Bartók, Appl. Catal. A: Gen. 2007, 319, 193.

91. P. Kukula, R. Prins, Topics. Catal. 2003, 25, 29.

92. F. Glorius, Org. Biomol. Chem. 2005, 3, 4171.

93. M. Maris, W. -R. Huck, T. Mallat, A. Baiker, J. Catal. 2003, 219, 52.

94. M. Maris, T. Bürgi, T. Mallat, A. Baiker, J. Catal. 2004, 226, 393.

95. M. Maris, T. Mallat, E. Orglmeister, A. Baiker, J. Mol. Catal. A: Chem. 2004, 219, 371.

96. Gy. Szőllősi, P. Forgó, M. Bartók, Chirality 2003, 15, S82.

97. Gy. Szőllősi, A. Chatterjee, P. Forgó, M. Bartók, F. Mizukami, J. Phys. Chem. A 2005, 109,860 .

98. H. -U. Blaser, H. Hönig, M. Studer, C. Wedemeyer-Exl, J. Mol. Catal. A: Chem. 1999, $139,253$.

99. N. J. Colston, R. P. K. Wells, P. B. Wells, G. J. Hutchings, Catal. Lett. 2005, 103, 117.

100. N. J. Coulston, E. L. Jeffery, R. P. K. Wells, P. McMorn, P. B. Wells, D. J. Willock, G. J. Hutching, J. Catal. 2006, 243, 360.

101. R. Hernández Valdés, L. Purez, M. Gomes Jr., C. E. S. J. Marques, D. A. G. Aranda, M. L. Bastos, A. L. Gemal, O. A. C. Antunes, Catal. Commun. 2004, 5, 631.

102. M. Gomes Jr., R. Hernández Valdés, C. E. S. J. Marques, M. L. Bastos, D. A. G. Aranda, O. A. C. Antunes, React. Kinet. Catal. Lett. 2006, 87, 19.

103. Gy. Szöllösi, E. Szabó, M. Bartók, Adv. Synth. Catal. 2007, 349, 405.

104. K. Borszeky, T. Mallat, R. Aeschiman, W. B. Schweizer, A. Baiker, J. Catal. 1996, 
$161,451$.

105. Gy. Szőllősi, I. Kun, M. Bartók, Chirality 2001, 13, 619.

106. P. Kirsch, Modern Flouroorganic Chemistry: Synthesis, Reactivity and Applications, Wiley-VCH: New York, 2004.

107. G. London, Gy. Szőllősi, M. Bartók, J. Mol. Catal. A: Chem. 2007, 267, 81.

108. H. Abe, K. Amii, K. Uneyama, Org. Lett. 2001, 3, 313.

109. M. von Arx, T. Mallat, A. Baiker, J. Catal. 2000, 193, 161.

110. K. Szőri, Gy. Szőllősi, M. Bartók, Adv. Synth. Catal. 2006, 348, 515.

111. K. Szőri, Gy. Szőllősi, M. Bartók, J. Catal. 2006, 244, 255.

112. Gy. Szőllősi, T. Varga, K. Felföldi, Sz. Cserényi, M. Bartók, Catal. Commun. 2008, 9, 421.

113. P. A. Meheux, A. Ibbotson, P. B. Wells, J. Catal. 1991, 128, 387.

114. N. Künzle, R. Hess, T. Mallat, A. Baiker, J. Catal. 1999, 186, 239.

115. N. Künzle, J. -W. Solèr, T. Mallat, A. Baiker, J. Catal. 2002, 210, 466.

116. T. Kubota, H. Kubota, T. Kubota, E. Moriyasu, T. Uchida, Y. Nitta, T. Sugimura, Y. Okamoto, Catal. Lett. 2009, 129, 387.

117. T. Sugimura, T. Uchida, J. Watanabe, T. Kubota, Y. Okamoto, T. Misaki, T. Okuyama, J. Catal. 2009, 262, 57.

118. T. Misaki, H. Otsuka, T. Uchida, T. Kubota, Y. Okamoto, T. Sugimura, J. Mol. Catal. A: Chem. 2009, 312, 48.

119. T. Sugimura, T. Y. Kim, Catal. Lett. 2009, 130, 564.

120. T. Sugimura, H. Ogawa, Chem. Lett. 2010, 39, 232.

121. L. Feiser, Experiments in Organic Chemistry, $3^{\text {rd }}$ ed., D. C. Health and Co., Boston, 1955, p. 182.

122. K. Felföldi, M. Sutyinszky, N. Nagy, I. Pálinkó, Synth. Commun. 2000, 30, 1543.

123. B. Halton, A. I. Maidment, D. L. Officer, J. M. Warnes, Aust. J. Chem. 1984, 37, 2119.

124. I. Pálinkó, A. Burrichter, G. Rasul, B. Török, G. K. S. Prakash, G. A. Olah, J. Chem. Soc., Perkin Trans. 1998, 2, 379.

125. K. Bowden, D. C. Parkin, Can. J. Chem. 1968, 46, 3909.

126. P. Chandra Ray, N. Munichandraiah, P. Kumar Das, Chem. Phys. 1996, 211, 499.

127. R. Fuchs, J. J. Bloomfield, J. Org. Chem. 1966, 31, 3423.

128. E. Maccarone, A. Mamo, D. Sciotto, M. Torre, J. Chem. Soc., Perkin II 1980, 161.

129. T. M. Babar, N. H. Rama, G. Qadeer, G. S. Khan, W. -Y. Wong, Acta Crystallogr. Sect. E 2006, E62, o4082.

130. R. W. Taft Jr., J. Am. Chem. Soc. 1957, 79, 1045.

131. R. W. Taft Jr., J. Phys. Chem. 1960, 64, 1805.

132. J. Hine, J. Am. Chem. Soc. 1960, 82, 4877.

133. R. Hess, T. Mallat, A. Baiker, J. Catal. 2003, $218,453$.

134. S. E. Boiadjiev, D. A. Lightner, J. Phys. Org. Chem. 1999, 12, 751.

135. A. P. G. Kieboom, H. van Bekkum, J. Catal. 1972, 25, 342.

136. J. A. K. Howard, V. J. Hoy, D. O'Hagan, G. T. Smith, Tetrahedron 1996, 52, 12613.

137. J. D. Dunitz, R. Taylor, Chem. Eur. J. 1997, 3, 89.

138. A. Vargas, F. Hoxha, N. Bonalumi, T. Mallat, A. Baiker, J. Catal. 2006, 240, 203.

139. M. von Arx, T. Mallat, A. Baiker, Angew. Chem. Int. Ed. 2001, 40, 2302.

140. Thales Nanotechnology H-Cube ${ }^{\mathrm{TM}}$ flow hydrogenerator, see www.thalesnano.com 


\section{ACKNOWLEDGEMENTS}

I am very grateful to my supervisor Professor Dr. Ferenc Fülöp, Head of the Institute of Pharmaceutical Chemistry, for his encouragement and the possibility for me to perform my Ph.D. work.

I wish to express my warmest thanks to my second supervisor, Dr. György Szőllösi, for his scientific guidance of my work, his encouragement and his useful advice.

My thanks are due to all members of the Stereochemistry Research Group of the Hungarian Academy of Sciences for their help and encouragement.

I am grateful to the Richter Gedeon Centenáriumi Alapítvány for financial support of my Ph.D. study from 1 September 2010 to 28 February 2011.

Finally, I would like to express my special thanks to my family for their love and support, without which this work could not have been completed. 


\section{ANNEX}

